\title{
Structure-Function Relationships in Rat Brainstem Subnucleus Interpolaris. X. Mechanisms Underlying Enlarged Spared Whisker Projections after Infraorbital Nerve Injury at Birth
}

\author{
Mark F. Jacquin, ${ }^{1}$ Daniel S. Zahm, ${ }^{1}$ Theodore A. Henderson, ${ }^{1}$ Judith P. Golden, ${ }^{1}$ Eugene M. Johnson, ${ }^{2}$ William \\ E. Renehan, ${ }^{3}$ and Bradley G. Klein ${ }^{4}$ \\ 'Department of Anatomy and Neurobiology, St. Louis University School of Medicine, St. Louis, Missouri 63104, \\ 2Department of Molecular Biology and Pharmacology, Washington University School of Medicine, St. Louis, Missouri \\ 63110, ${ }^{3}$ Division of Gastroenterology, Department of Medicine, Henry Ford Hospital, Detroit, Michigan 48202, and \\ ${ }^{4}$ Department of Biomedical Sciences, Virginia-Maryland Regional College of Veterinary Medicine, Virginia Polytechnic \\ Institute and State University, Blacksburg, Virginia 24061
}

Prior studies indicate that the central projections of noninfraorbital vibrissae occupy greater than normal transverse areas in the rat trigeminal brainstem complex after infraorbital nerve section at birth. Here, we assessed the development of this phenomenon and possible underlying mechanisms. Cytochrome oxidase patches representing spared supraorbital (SO) or posteroorbital (PO) whiskers in the trigeminal subnucleus interpolaris (SpVi) were not reliably larger than those on the control side $24 \mathrm{hr}$ after the infraorbital lesion. By $72 \mathrm{hr}$, SO and PO patches were $91 \%$ and $28 \%$ larger than those on the control side. Reliable increases were also observed on postnatal day 5 (PND5), PND7, and PND10 for the SO $(59 \%, 65 \%, 66 \%)$ and PO $(23 \%, 44 \%, 51 \%)$ patches.

To test the hypothesis that central reorganization reflects the maintenance of peripheral supernumerary axons, myelinated and unmyelinated axons in SO vibrissa follicles were counted at PND0, PND7, PND17, and PND60. A corollary hypothesis, that peripheral regeneration errors result in both SO and surviving infraorbital axons contributing to central so patches, was tested with retrograde double-labeling methods. Both hypotheses were rejected. Thus, enlargement of SO patches is not due to either the maintenance of an immature peripheral innervation pattern, or regeneration of infraorbital axons into SO follicles.

To determine if the enlargement of SO and PO patches produced by infraorbital nerve section is due to an activitydependent competitive disadvantage imposed upon infraorbital afferents, TTX or bupivicaine was applied to the intact infraorbital nerve over the first 5-9 postnatal days. Brainstem maps developed normally and SO and $P O$ patch areas were unaffected. Thus, impulse activity-based mechanisms do not appear to contribute to injury-induced patch enlargement.

\footnotetext{
Received July 28, 1992; revised Jan. 8, 1993; accepted Jan. 25, 1993.

We thank P. Waite, P. Osborne, and N. Hobart for valued assistance. This work was supported by NIH Grants DE07734 and DE07662 to M.F.J. and W.E.R., DE08966 to B.G.K., NS23805 to D.S.Z., and NS24679 to E.M.J.

Correspondence should be addressed to Dr. Mark F. Jacquin, Department of Anatomy and Neurobiology, St. Louis University School of Medicine, South Grand Boulevard, St. Louis, MO 63104.

Copyright (C) 1993 Society for Neuroscience $0270-6474 / 93 / 132946-19 \$ 05.00 / 0$
}

To test the hypothesis that patch enlargement is due to central collateral reorganization, intra-axonal recording and staining methods were applied to control and spared-whisker primary afferents in adult rats. Total bouton or collateral numbers did not differ in SpVi; however, arbor areas were reliably larger in experimental $\left(14,879 \pm 350 \mu \mathrm{m}^{2}\right)$ versus control $\left(5527 \pm 1811 \mu \mathrm{m}^{2}\right)$ fibers. Thus, patch enlargement reflects axon arbor expansion, but not collateral or terminal sprouting, in spared-whisker collaterals. If arbor expansion is due to "passive" encroachment of collaterals into infraorbital terminal space vacated by axotomy-induced ganglion cell death, then rescuing injured ganglion cells and their central projections with supplemental NGF would prevent patch enlargement. This did not occur. Patches enlarged as in animals whose ganglion cells were not rescued.

Thus, central arbor expansion in spared-whisker primary afferents underlies the altered somatotopy induced by neonatal nerve damage. The inductive signal for arbor encroachment into infraorbital neuropil remains to be determined, although it would not appear to be related to injury-induced activity alterations or ganglion cell death.

[Key words: trigeminus, development, sprouting, barrels, vibrissae, pattern formation, somatosensory system]

The purpose of the present study was to uncover the mechanism(s) subserving injury-induced reorganization in developing somatosensory system maps. While demonstrations of such phenomena are numerous (for recent reviews, see Frank and Mendelson, 1990; Killackey et al., 1990; Woolsey, 1990), little is known of the factors responsible for lesion-induced map alterations. The model we have chosen in which to address this issue is the rat trigeminal (V) system, in particular the first- and second-order neurons in $\mathrm{V}$ brainstem subnucleus interpolaris (SpVi) that are responsive to single whiskers on the face, have highly stereotyped morphologies, and as a group display a patterned representation of the facial whiskers (Jacquin et al., 1986, 1988). It is now established that infraorbital nerve damage sustained during fetal (Rhoades et al., 1989; Chiaia et al., 1992) or early postnatal development interrupts whisker-related pattern formation. Van der Loos and Woolsey (1973) were the first to 
demonstrate the latter when they showed that cortical barrels do not develop when the whisker follicles are cauterized at birth. Others have subsequently shown that subcortical "barrels" and associated axonal projection patterns are similarly perturbed by peripheral lesions inflicted during early development (reviewed in Woolsey, 1990).

Of particular importance to the present study is the observation that the central representations of the noninfraorbital whiskers, namely, the two above the eye (supraorbital, SO) and the one behind the eye (posteroorbital, PO), occupy greater than normal transverse areas in the adult rat's $\mathrm{V}$ brainstem complex following infraorbital nerve section at birth. The most compelling demonstration of such "spared-whisker" plasticity is that of Waite and de Permentier (1991). They used transganglionic labeling methods to show that the central projections of the PO vibrissal nerve occupy 1.8-2.3 times their normal transverse areas in $\mathrm{V}$ subnuclei principalis, oralis, and $\mathrm{SpVi}$ following infraorbital nerve section at birth. Waite (1984) and Jacquin (1989) used multi- and single-unit recording methods, respectively, to document significantly enlarged $\mathrm{V}$ brainstem areas containing cells responsive to deflection of the SO and PO whiskers. V regions exhibiting heightened glucose utilization are also larger than normal following associatively paired, single whisker stimulation (Hand et al., 1990), or selective sparing of single vibrissae from infraorbital nerve damage (Melzer et al., 1988).

Enlarged spared-whisker representations in the brainstem are reflected in similar types of map reorganization in the SI barrel cortex (e.g., Waite, 1984; Durham and Woolsey, 1985; Kossut et al., 1988). Therefore, cortical map changes induced by neonatal deafferentation may be due, at least in part, to subcortical events. To explain cortical plasticity, one must therefore be able to explain subcortical plasticity. The results of Waite and de Permentier (1991) provide an indication that subcortical plasticity is a direct reflection of altered primary afferent projection patterns. The present article describes experiments to assess potential mechanisms underlying enlarged spared-whisker projections following infraorbital nerve injury.

Enlarged central projections from spared vibrissae following neonatal infraorbital injury could occur by any or all of the following mechanisms: maintenance of an immature projection pattern, peripheral regeneration errors, altered competitive substrates that normally serve to constrain arbor dimensions in the developing $\mathrm{V}$ system, central or peripheral sprouting, or central arbor expansion and/or displacement. There are precedents for each of these non-mutually exclusive mechanisms in the developing V system (e.g., Renehan et al., 1989; Woolsey, 1990; Rhoades et al., 1991; Chiaia et al., 1992). Therefore, we tested the following hypotheses with anatomical and physiological methods: (1) SO patch enlargement reflects the maintenance of supernumerary axons in spared-whisker follicles; (2) peripheral regeneration errors result in both spared SO and surviving infraorbital axons contributing to the SO nerve, therein resulting in central SO patches that also contain infraorbital axons; (3) SO and PO patch enlargement is due to an activity-dependent competitive disadvantage conferred upon injured infraorbital afferents, relative to spared SO and PO afferents; (4) SO and $P O$ patch enlargement is due to central collateral reorganization; and (5) SO and PO patch enlargement is induced by reduced primary afferent inputs to adjacent regions normally receiving infraorbital projections.

Portions of this work have been published in abstract form (Young et al., 1990; Hobart et al., 1991).

\section{Materials and Methods}

A total of 101 Sprague-Dawley rats, of either sex, provided data. Housing and treatment conditions adhered to federally prescribed guidelines. Except where noted, all animals were subjected to left infraorbital nerve transection within 2-12 hr of birth under hypothermal anesthesia (Jacquin and Rhoades, 1983, 1985). In an attempt to minimize lesion variability, all surgeries were done by one person (M.F.J.) and all nerve sections were performed at the level of the infraorbital foramen. The time of death was scheduled relative to the time of birth, rather than the time of nerve section. For example, cases designated as perfused on postnatal day 3 (PND3) survived for $72 \mathrm{hr}$ postnatally.

Identification and measurement of $S O$ and $P O$ patches in the $V$ brainstem complex. Cytochrome oxidase histochemistry was used as a marker to study the development of enlarged central representations of the SO and $P O$ whiskers in neonatally deafferented SpVi. To determine which cytochrome patches correspond to these whiskers, 10 primary afferent axons responsive to deflection of either an SO or PO whisker were impaled in the V spinal tract at the level of SpVi and filled with horseradish peroxidase, using published methods (Jacquin et al., 1986, 1988). Six normal adult rats were required to recover 10 such axons. Following perfusion, tissue sectioning, and diaminobenzidine histochemistry, the locations of each stained fiber's collaterals in SpVi's transverse plane were plotted relative to the inner borders of the $\mathrm{V}$ spinal tract. Arbor locations, relative to the $\mathrm{V}$ spinal tract and nucleus, were used to determine which cytochrome patches represent SO and PO whiskers.

Thirty-four neonatally nerve-damaged animals were killed on PND1, PND1.5, PND3, PND5, PND7 $(N=6$ each), or PND10 $(N=4)$. Following deep barbiturate anesthesia, pups were perfused with saline followed by fixative (McLean and Nakane, 1974). Frozen transverse sections of the brainstems were taken at $60 \mu \mathrm{m}$ and processed for cytochrome oxidase histochemistry using methods described by WongRiley (1979). Each section through SpVi containing a cytochrome patch that corresponded to the SO and/or PO whiskers was viewed at $200 \times$ magnification on a Nikon Optiphot microscope. Patch borders were traced onto a graphics tablet through a drawing tube, and a median transverse area was calculated from at least three sections. In each case, a ratio of the area on the experimental to control sides (left:right) was then determined from the medians. Statistically reliable differences in the raw data were assessed by a two-way analysis of variance, using a $p<0.05$ cutoff, with age and treatment considered. Post hoc $t$ tests were then used to pinpoint age differences, with appropriate adjustments for multiple comparisons.

Axon numbers in $S O$ whisker follicle nerves. In 11 neonatal nervesectioned animals killed on PND7 $(N=3)$, PND17 $(N=3)$, or PND60 $(N=5)$, total numbers of myelinated and unmyelinated axons in one left and one right $\mathrm{SO}$ vibrissal nerve were determined. A left SO follicle was also taken at birth from four normal newborns to assess the follicle innervation at the time of the lesion. At all ages, only fibers in the deep vibrissal nerve were considered (Waite and Jacquin, 1992). Vibrissal nerves were processed for electron microscopic analysis using previously described methods (Klein et al., 1988). Briefly, after deep barbiturate anesthesia, rats were perfused with saline and an aldehyde fixative. SO follicles were dissected, fixed in osmium, and resin embedded, and thin sections $(60 \mathrm{~nm})$ were taken from the region between the vibrissal ncrve entry point and the Ringwulst. Thin sections were viewed with a Zeiss transmission electron microscope and photographic montages of each nerve were made at a final magnification of at least $4300 \times$. Counts were obtained with the aid of a magnifying glass and without knowledge of whether the material came from the experimental left or control right side. Differences between counts obtained from experimental and control sides, and from follicles of differing ages, were assessed with abovedescribed statistical methods.

Retrograde double-labeling experiments. Six rats were used to determine if regenerating infraorbital axons supplied ipsilateral SO follicles, therein resulting in both $\mathrm{SO}$ and surviving infraorbital axons contributing to the SO follicle. Within $1 \mathrm{hr}$ of birth, multiple injections of true blue (Sigma; $2.5 \%$ in water) totaling approximately $1 \mu$ l were made in the left whisker pad through glass pipettes fitted with wire plungers. Eight hours were allowed for chronic retrograde labeling of $V$ ganglion cells that projected to the left whisker pad at birth, at which time the left infraorbital nerve was transected as described above. Sixty days later, each of the two left SO follicles was isolated and injected with diamidino yellow (Sigma; $2.5 \%$ in water) according to the methods described in Klein and Rhoades (1985). After a 3 d survival period, animals were processed according to Klein et al. (1988) to reveal blue 
and yellow fluorescence in the left $\mathrm{V}$ ganglia, mystacial pads, and SO follicle regions. Tissue was examined with a Nikon Optiphot microscope equipped with bright-field, dark-field, and episcopic fluorescence optics. The numbers of double-labeled $\mathrm{V}$ ganglion cells containing both a yellow nucleus and blue cytoplasm were determined for each case.

Infraorbital nerve block experiments. To determine whether $\mathrm{SO}$ and PO patch enlargement is due to relative changes in impulse activity between injured and spared afferents produced by infraorbital nerve section, tetrodotoxin ( $N=3$ for each age group) or bupivicaine $(N=4)$ was applied from birth to block infraorbital nerve impulses during the first 3,5, 7, or 9 postnatal days. The methods used to achieve total unilateral impulse blockade during this period are described in detail in Henderson et al. (1992). Briefly, mystacial whiskers were trimmed daily and new slices of a slow-release polymer (Elvax-40) containing $0.001 \mathrm{M}$ tetrodotoxin were inserted under the left infraorbital nerve during hypothermic anesthesia within $8 \mathrm{hr}$ of birth and replaced every $8 \mathrm{hr}$. Implants removed from experimental pups after $8 \mathrm{hr}$ and applied to the infraorbital nerve of another rat eliminated multiunit activity in the $\mathrm{V}$ ganglion evoked by mystacial whisker stimulation (see Fig. 1 in Henderson et al., 1992). Other newborn rats received injections of bupivicaine, a long-acting local anesthetic, into the left whisker pad through glass micropipettes every $2.5-4 \mathrm{hr}$ with daily whisker trimming. After 5-9 d, tetrodotoxin- or bupivicaine-treated animals were killed and brainstems were processed for cytochrome oxidase activity using abovedescribed methods. SO and PO patch sizes in SpVi were determined in the transverse plane and experimental effects were assessed as described above.

Primary afferent collateral morphology experiments. To determine whether injury-induced patch enlargement reflected collateral reorganization in the brainstem and, if so, the nature of the reorganization, intra-axonal recording and horseradish peroxidase staining methods were used to compare 10 control and 10 experimental SO or PO primary afferents. Many of the electrophysiological, anatomical, and analytic methods used are provided in Jacquin et al. (1986, 1988). Briefly, in six adults ( $>60 \mathrm{~d}$ old) subjected to left infraorbital nerve section at birth, individual primary afferents responsive to deflection of either the SO or $\mathrm{PO}$ whisker were impaled in the left $\mathrm{V}$ spinal tract at the level of SpVi with glass micropipettes and injected with horseradish peroxidase. Following a barbiturate overdose, rats were perfused with aldehydes and $100-\mu \mathrm{m}$-thick, transverse, frozen sections of the brainstem were processed for cobalt-intensified diaminobenzidine histochemistry. The total number of primary collaterals given off into SpVi (see Jacquin et al., 1988, for border definitions) was determined for each fiber, as well as the total number of terminal boutons stained for each collateral in $\mathrm{SpVi}$. The average transverse area subtended by each terminal arbor in $\mathrm{SpVi}$ was also determined by tracing arbor envelope outlines onto a graphics tablet.

Our method of determining transverse arbor areas has not been adequately described in prior reports; therefore, this method is detailed as follows. For each section containing labeled boutons in SpVi, an arbor envelope outline was produced by plotting all of the boutons and connecting the outermost boutons on the drawing. Objective criteria were developed that resulted in "tight fitting" arbor envelopes, as illustrated in Figure 13. Starting at the arbor's dorsalmost point and moving in a clockwisc dircetion, boutons were connected by lines to produce an angle with the previously drawn line that most closely approximated $90^{\circ}$, but never less than $90^{\circ}$. If, in the clockwise course of producing these lines, a line produced less than a $90^{\circ}$ angle with the previously drawn line, the prior connector was relaxed to connect farther outlying boutons such that the $90^{\circ}$ minimum fit could be maintained. Exceptions to these criteria were applied to cases where (1) greater than $100-\mu \mathrm{m}$-long lines bound areas that were clearly devoid of boutons (e.g., Fig. $13 g$ ), at which point more narrow angles were subtended, although never to the extent that one bouton linked more than two connectors; or (2) it was impossible to use a greater than $90^{\circ}$ connector, such as at an extreme jagged edge of a terminal cluster (e.g., the dorsolateral edge of the arbor in Fig. 13a). These outlines were then traced onto a graphics tablet that provided data on mean arbor area and circumference. Analysis of variance and post hoc $t$ tests were used to test for significant differences between experimental and control axons on all of the abovedescribed measures pertaining to single fiber morphology.

$V$ ganglion cell rescue experiments. To determine whether the extensive ganglion cell death and axon degeneration (Jacquin and Rhoades, 1983; Chiaia et al., 1987; Golden et al., 1993; Henderson et al., 1993) produced by neonatal infraorbital nerve injury is a necessary condition for $\mathrm{SO}$ and $\mathrm{PO}$ patch enlargement, 18 newborn rats were given subcutaneous injections of $5 \mathrm{mg} / \mathrm{kg}$ of $2.5 \mathrm{~S}$ nerve growth factor (Bucchini and Angeletti, 1969) prior to, and every day after, left infraorbital nerve section within $12 \mathrm{hr}$ of birth. Animals were killed on PND1, PND3, PND5 $(N=5$ each), or PND7 $(N=3)$ and their brainstems were processed for cytochrome oxidase histochemistry with the above-described methods. In each case, left and right $\mathrm{V}$ ganglia were embedded in paraffin, $10 \mu \mathrm{m}$ horizontal sections were stained with cresyl violet, and the total number of cells in each ganglion was estimated using a modified stereological method (Coggeshall et al., 1990; Coggeshall, 1992). Cytochrome patches in SpVi corresponding to the SO and PO whiskers were measured and experimental effects were assessed as described above.

To determine whether the ganglion cells rescued from axotomy-induced death maintain their central projections, another group of five newborn rats were subjected to the above-described nerve growth factor injection and infraorbital lesion regimen. Following perfusion on PND5, an anterograde marker [1, $1^{\prime}$-dioctodecyl-3,3,3,3'-tetramethylindocarbocyanine perchlorate (DiI), Molecular Probes] was applied to the severed $V$ sensory root and the central labeling pattern was compared to the labeling obtained from five littermates that did not receive nerve growth factor injections following infraorbital injury. The methods used to process the brainstems for DiI labeling were those developed by Senft and Woolsey (1991).

\section{Results}

Identification and developmental time course of SO and PO patch enlargement in $S p V i$

Intra-axonal staining experiments in normal adults showed that collaterals from SO or PO primary afferents arborized in characteristic locations in SpVi with shapes that were typical of mystacial whisker primary afferents (Jacquin et al., 1986). As shown in Figure 1, taken from a case where both an SO and a PO fiber were stained, collaterals were given off intermittently in SpVi's rostrocaudal extent and they arborized in a circumscribed manner with dimensions approximating that of the corresponding cytochrome patches described below (approximately $75 \mu \mathrm{m}$ in average diameter). SO and $\mathrm{PO}$ arbors always occurred juxtaposed with the ventral $\mathrm{V}$ spinal tract, with the $\mathrm{SO}$ arbors located ventral to $\mathrm{PO}$ arbors. Moving rostrally within $\mathrm{SpVi}$, the $\mathrm{SO}$ arbors tended to drift ventromedial to the $\mathrm{PO}$ arbors.

$\mathrm{SO}$ and $\mathrm{PO}$ whisker primary afferent projections were reliably represented in SpVi by distinct cytochrome oxidase patches (Figs. 2, 3). Three patches corresponding in location to the abovedescribed SO and PO arbors were identified in SpVi on PND1.5, PND3, PND5, PND7, and PND10. On PND1, only one SO patch was visible. Identification of the $\mathrm{SO}$ and $\mathrm{PO}$ patches was also aided by their consistent location relative to the orderly array of patches representing the mystacial whiskers (e.g., Belford and Killackey, 1979; Durham and Woolsey, 1984). The two SO patches occurred ventral to the caudal A-row whisker patches, whereas the one $\mathrm{PO}$ patch occurred lateral to the Band C-row whisker patches. All three of these patches were most distinct in the caudal one-half of SpVi, at the level of the obex, and they extended farther caudally than mystacial whisker patches, as $\mathrm{SpVi}$ is displaced progressively laterally and ventrally by subnucleus caudalis (Jacquin et al., 1988).

In neonatally deafferented $\mathrm{SpVi}$, the most darkly stained and clearly demarcated cytochrome oxidase patches were those representing the SO and PO whiskers, although some mystacial row-related staining persisted through PND1.5 (Fig. 2). Patches representing the $\mathrm{SO}$ and $\mathrm{PO}$ whiskers were reliably larger than the corresponding patches on the intact, control side by PND1.5 and PND3, respectively, and these differences persisted through the last time point examined (PND10; Fig. 3). Left:right differences are plotted for each postnatal day in Figure 4. By PND10, 

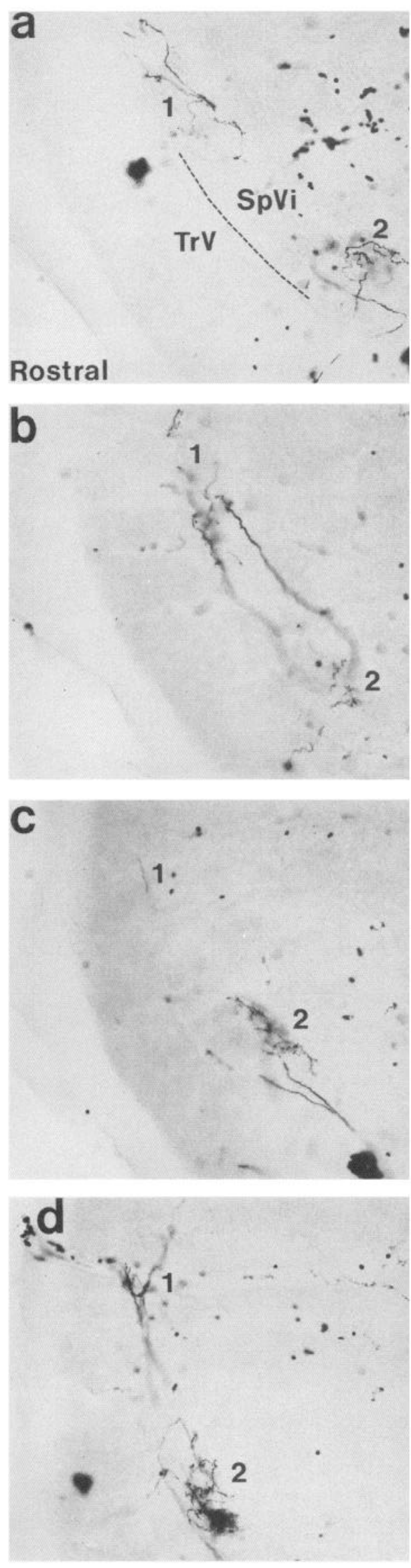
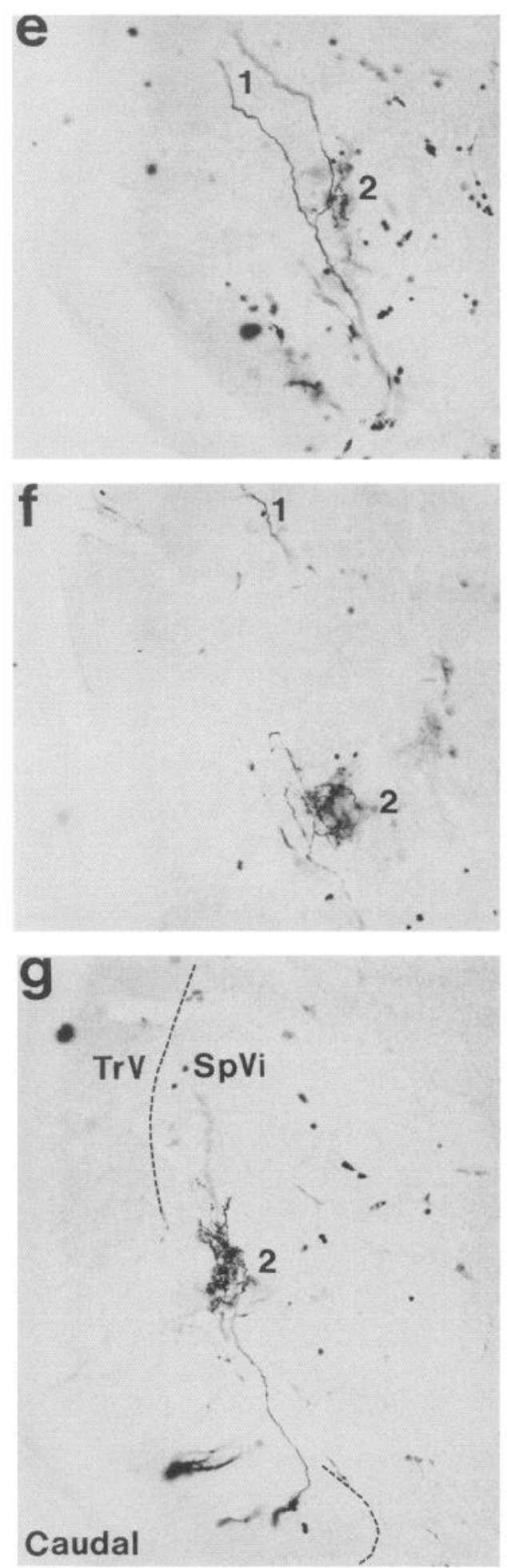

\#SW1: Normal Adult

$200 \mu \mathrm{m}$
Figure 1. Intra-axonal staining of $\mathrm{V}$ primary afferents responsive to deflection of the SO or PO vibrissae in a normal adult rat. HRP-labeled collaterals in the left SpVi are shown in transverse sections moving from rostralmost $(a)$ to caudalmost $(g)$. Arbors denoted by a 1 are from a fiber that responded phasically to sustained displacement of the PO whisker in either of the four cardinal directions. Arbors denoted by a 2 are from a fiber that responded tonically to sustained caudal or dorsal deflections of the rostral SO whisker. In $a$ and $g$, the border between the $\mathrm{V}$ spinal tract $(\operatorname{Tr} V)$ and $\mathrm{SpVi}$ is indicated by a broken line. Note that the arbors from both fibers abut the $\mathrm{TrV}$ in consistently segregated positions. 
p1

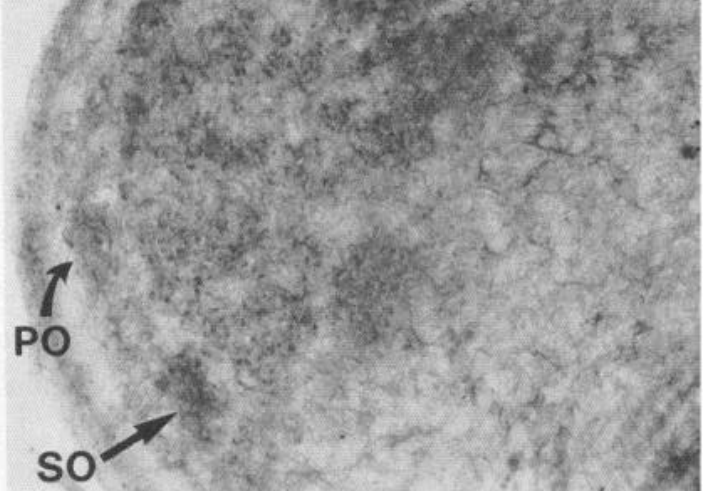

01.5

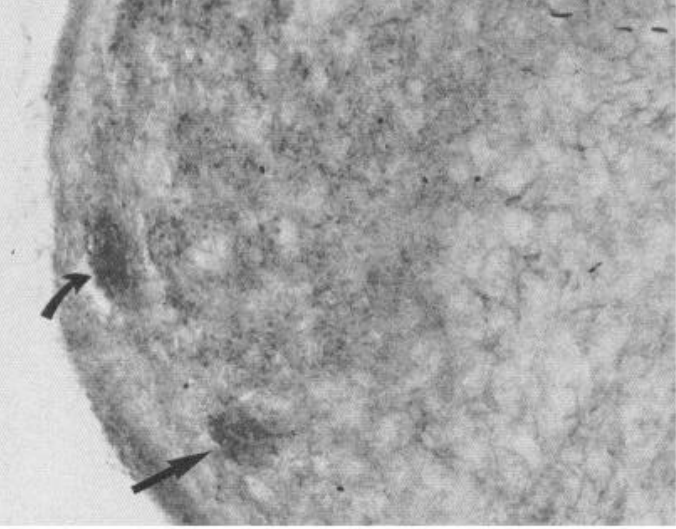

\section{p3}

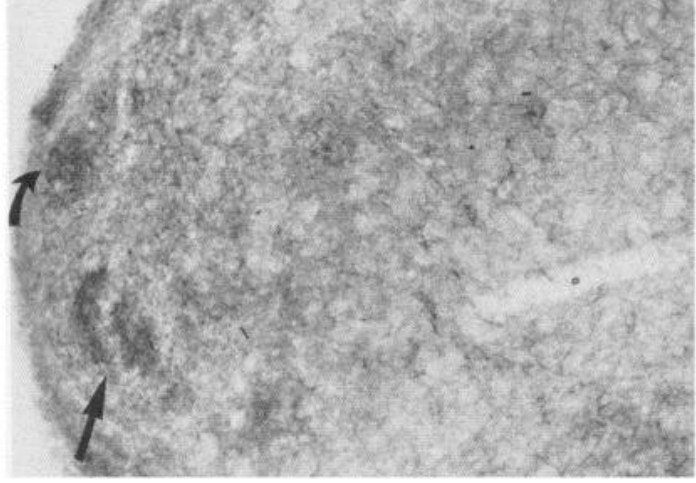

p5

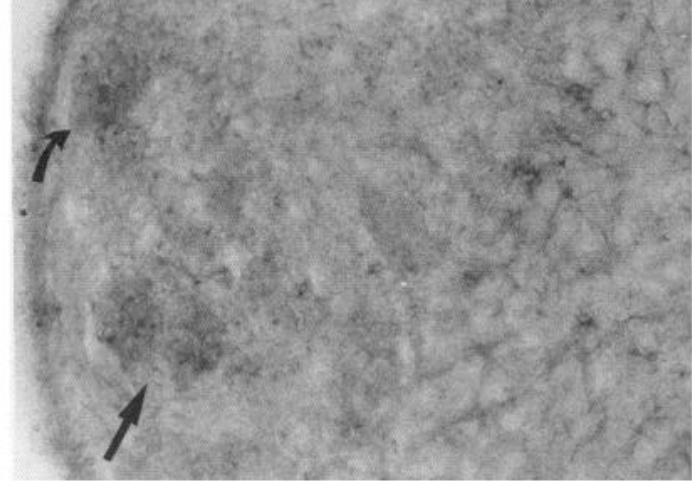

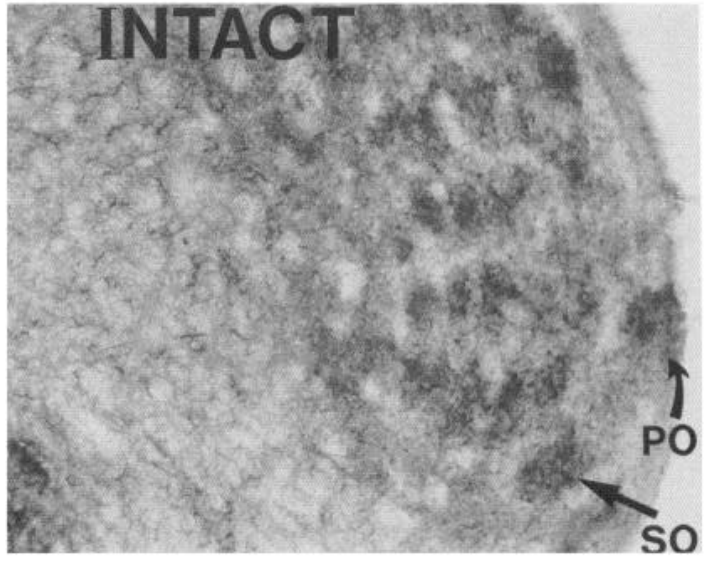
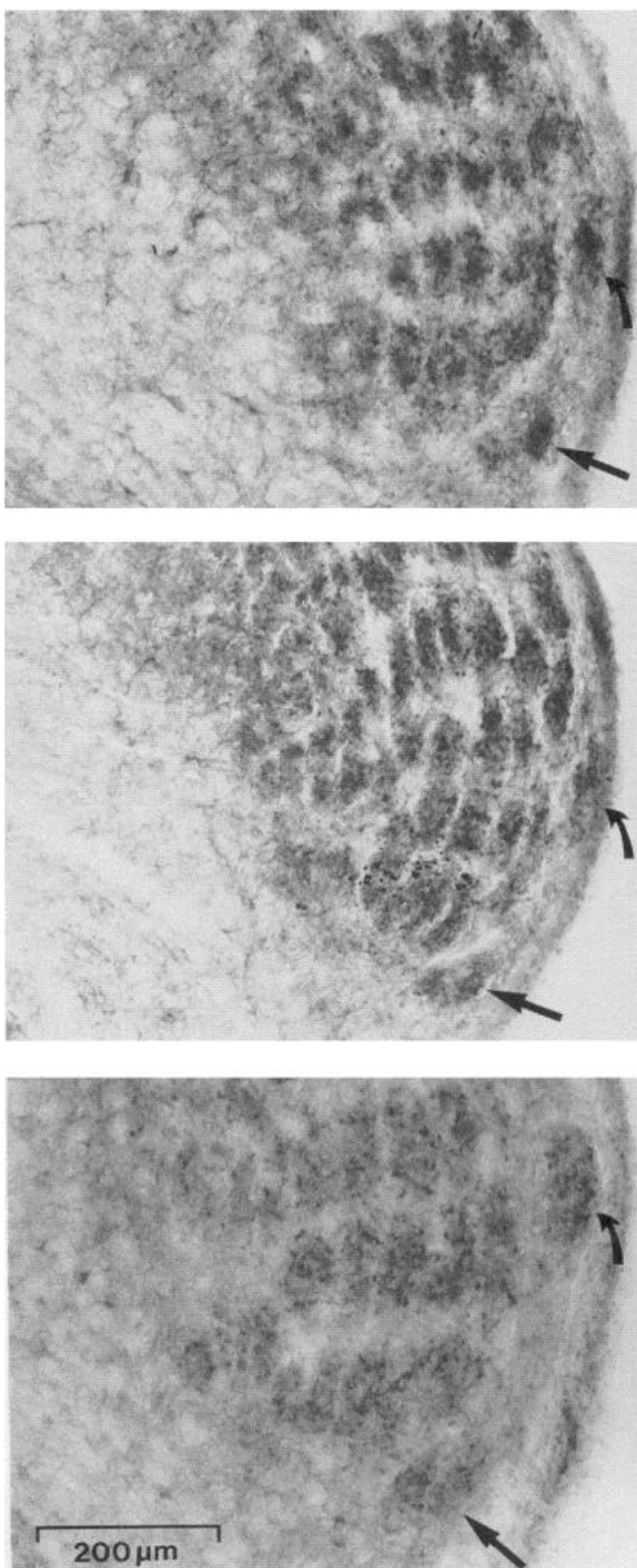

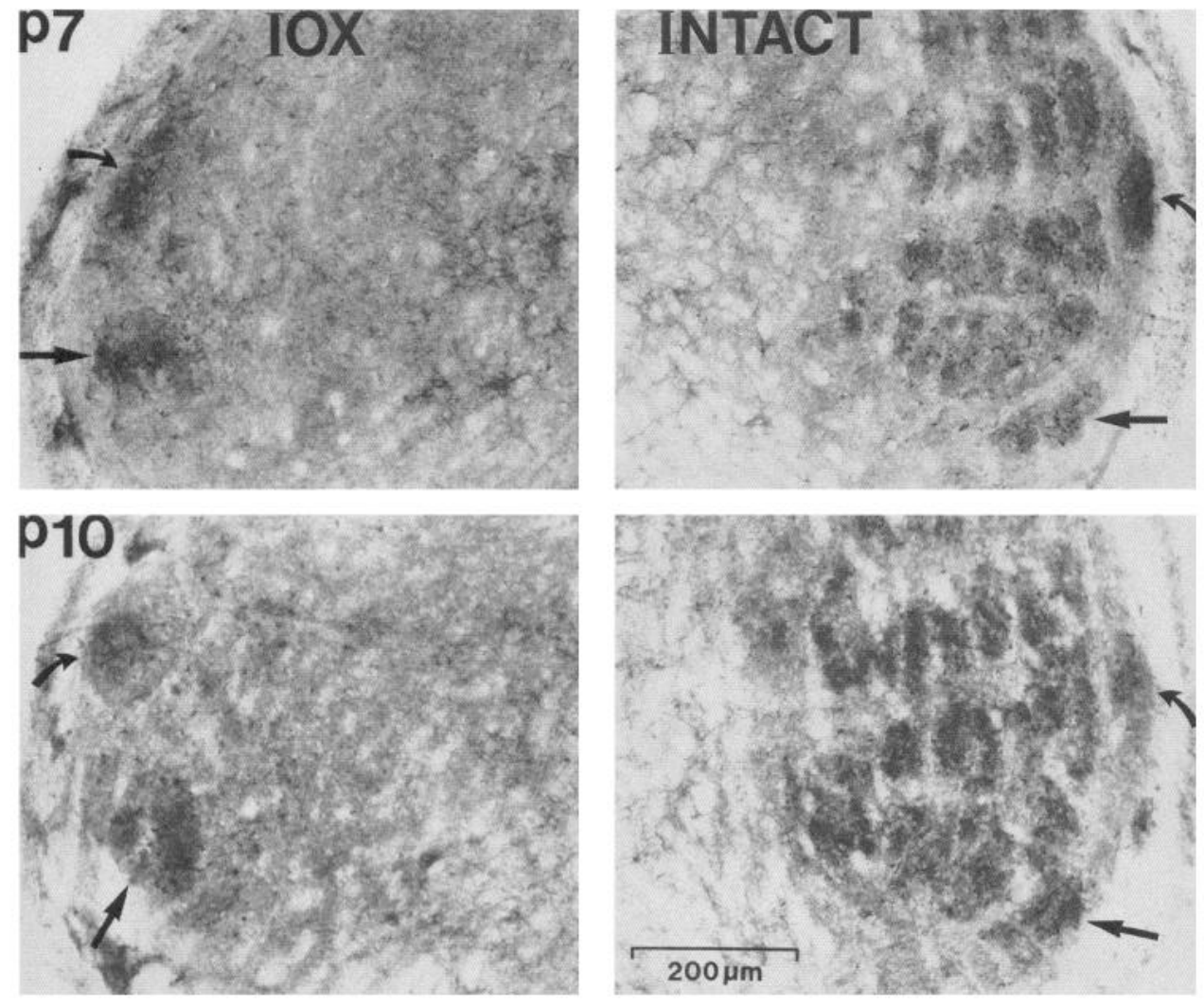

Figure 3. Infraorbital nerve sectioninduced enlargement of the SO and PO patches in $\mathrm{SpVi}$ is also evident in cytochrome oxidase-stained sections from cases killed on PND7 and PND10. The experimental left and control right sides from a PND7 (top) and P10 (bottom) case are shown. See Figure 2 for conventions. the SO and PO patches were $66 \%$ and $51 \%$ larger, respectively, than their counterparts on the control side.

\section{Supernumerary axons in spared SO whisker follicles?}

In newborn rats, an average $( \pm \mathrm{SD})$ of $101 \pm 25$ axons were counted in the SO deep vibrissal nerve, all but three of which were unmyelinated. On PND7, there were $122 \pm 6$ and $118 \pm$ 9 axons in the experimental and control nerves, respectively. Figure 5 illustrates the ease with which unmyelinated axons were identified in this material. On PND17, there were $166 \pm 12$ and $156 \pm 38$ axons in experimental and control nerves, respectively. By PND60, there were $180 \pm 43$ and $170 \pm 58$ axons in experimental and control nerves, respectively. Electron microscopic montages taken from the left and right deep vibrissal nerves of a PND60 case are provided in Figure 6 . At none of the ages sampled did a difference between experimental and control axon numbers reach statistical significance. Myelinated and unmyelinated axon counts for each of PND7, PND17, or PND60 also did not differ between experimental and control nerves (Fig. 7). A significant accrual of unmyelinated axons between PND7 and PND17 led to a statistically reliable increase in total axon number during this interval.

Thus, the induction of enlarged central representations of the SO whiskers by neonatal infraorbital nerve injury does not reflect the maintenance of supernumerary axons in spared SO whisker follicles.

\section{Regeneration errors?}

As illustrated in Figure 8, large numbers of $\mathrm{V}$ ganglion cells were retrogradely labeled by true blue injections into the mystacial pad prior to nerve section on the day of birth, and by diamidino yellow injections into the ipsilateral SO whisker follicles in adulthood. However, no double-labeled cells were observed in any of the six cases. Thus, peripheral regeneration errors did not result in an aberrant infraorbital projection to SO follicles.

\section{Activity-dependent competitive interactions?}

As previously reported (Henderson et al., 1992), infraorbital maps developed normally following chronic TTX or bupivicaine application to the infraorbital nerve from birth. The patterning (Fig. 9) and areal dimensions (Fig. 10) of SO and PO cytochrome patches in $\mathrm{SpVi}$ were also unaffected at each of the four postnatal ages tested. Thus, infraorbital injury-induced enlargement of the SO and PO patches would not appear to reflect an activity-based competitive disadvantage imposed upon axotomized and surviving infraorbital axons, relative to spared $\mathrm{SO}$ and $\mathrm{PO}$ primary afferent projections to $\mathrm{SpVi}$.

\section{Central axon collateral reorganization?}

HRP staining of physiologically identified SO and PO fibers revealed alterations in their collateral morphologies in $\mathrm{SpVi}$ following infraorbital nerve section at birth. Representative col-

Figure 2. Cytochrome oxidase histochemistry reveals patches in SpVi representing the two SO and one PO whiskers on postnatal $(P)$ days $1,1.5$, 3 , and 5. These patches undergo a progressive enlargement following infraorbital nerve section $(I O X)$ on the day of birth $(P 0)$, relative to the intact, right side. Mystacial whisker patterns on the sectioned side also rapidly deteriorate in SpVi during these periods. SO patches are indicated by straight arrows, the PO patch by curved arrows; $60-\mu \mathrm{m}$-thick transverse sections at the level of the obex. 


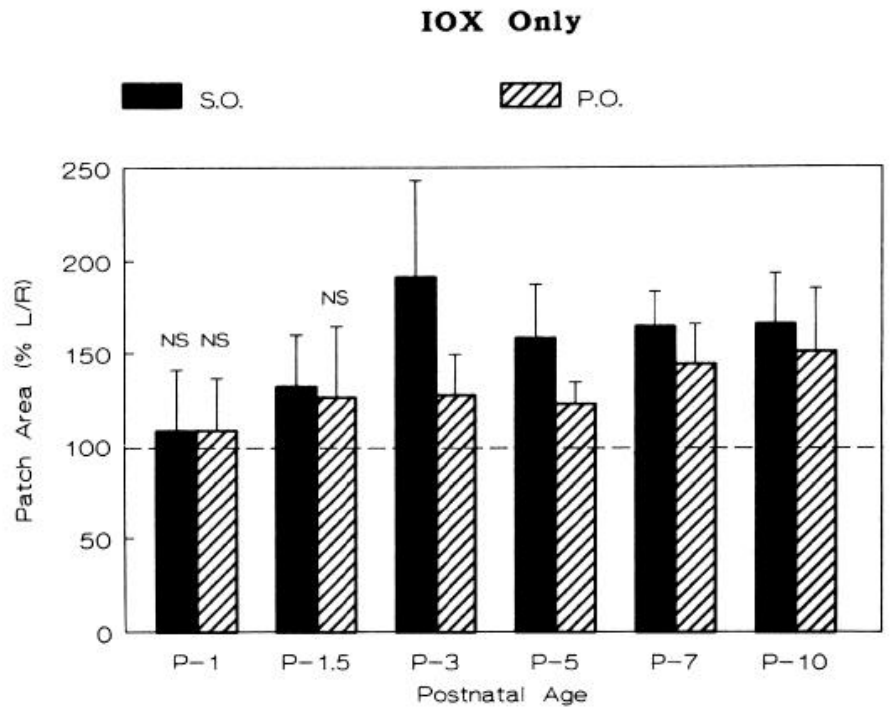

Figure 4. Transverse areal measurements of the cytochrome oxidasestained SO and PO patches on the infraorbital nerve sectioned (IOX) left $(L)$ side relative to those on the control right $(R)$ side. Lesion-induced increases were not significant (NS) on PND1 and PND1.5 (for the PO whisker only). Data were reduced to a median left:right percentage from multiple sections within single cases; the means \pm SDs of these values from all cases are shown here, with $100 \%$ indicating no difference from control. The consistently greater increase in the SO, relative to the $\mathrm{PO}$, patches likely reflects there being two SO whiskers and only one PO whisker.

laterals from experimental and control SO-responsive axons are illustrated in a single focal plane in Figure 11. A typical experimental SO fiber is also reconstructed through the entirety of $\mathrm{SpVi}$ in Figure 12 (presented in a format comparable to that of Fig. 9 in Jacquin et al., 1986, showing a control SO fiber). While they appeared normal in their transverse orientations and general locations, experimental $\mathrm{SO}$ and $\mathrm{PO}$ arbors were more widespread in the transverse plane with reduced bouton densities. Note in particular the collaterals shown in panels $0.4,0.6,0.9$, and 1.2 of Figure 12 whose transverse dimensions span well beyond that of the areas known to be responsive to a single whisker in normal animals. Moreover, most experimental collaterals had at least one secondary branch that extended beyond the region of the primary arbor focus (straight solid arrows in Fig. 11), whereas such secondary branches in control fibers always curved back towards the region of primary arbor focus (curved arrows in Fig. 11). As a result, the average transverse area subtended by experimental arbors was significantly greater than that of functionally equivalent fibers from the intact side $\left(14,879 \pm 350 \mu \mathrm{m}^{2}\right.$ vs $5527 \pm 1811 \mu \mathrm{m}^{2}$, respectively; $p<$ $0.01)$. This effect is most readily appreciated by comparing the arbor envelopes of experimental and control collaterals, as illustrated for selected SO collaterals in Figure 13. Experimental and control fibers did not, however, differ reliably in their collateral or bouton numbers in SpVi (Fig. 13, bar graphs).

Thus, SO and PO patch enlargement reflects a transverse expansion in single collateral arbors, and not altered collateral or terminal bouton numbers. In other words, a normal number of terminal boutons are dispersed over a wider target territory. The following experiment addressed one factor that might play a role in inducing $\mathrm{SO}$ and $\mathrm{PO}$ arbor expansion into neighboring neuropil deafferented by infraorbital injury at birth.
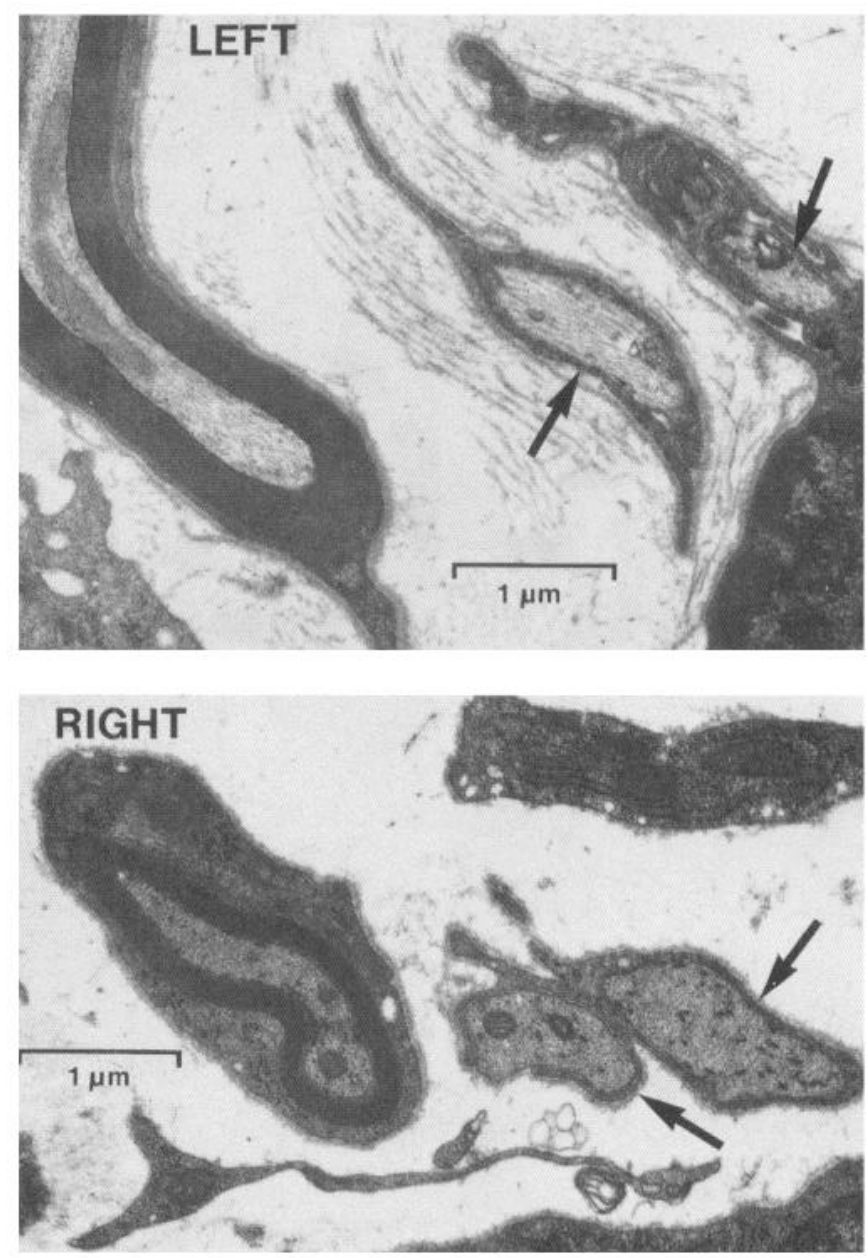

Figure 5. Electron micrographs from transverse sections through the deep vibrissal nerves in PND7 SO follicles ipsilateral ( $L E F T)$ and contralateral $(R I G H T)$ to the neonatally transected infraorbital nerve. $A r$ rows indicate unmyelinated fibers. A myelinated fiber is also shown in each plate.

\section{An inductive signal related to injury-induced ganglion cell death?}

As documented elsewhere (see Henderson et al., 1993, for details) where the same animals were used to address other issues, daily NGF injections rescued large numbers of $\mathrm{V}$ ganglion cells from axotomy-induced death. Significantly more cells existed in NGF-treated and axotomized ganglia than in axotomized and nontreated ganglia through PND7. Moreover, cases not receiving exogenous trophic support exhibited significant ganglion cell death by PND1. In NGF-treated cases, DiI transport revealed significant projections to infraorbital terminal regions in the $\mathrm{V}$ brainstem complex that were rendered largely devoid of primary afferent inputs when exogenous trophic support was not administered (Fig. 14). Thus, at least some of the ganglion cells rescued from axotomy-induced death through the first postnatal week maintained central projections to brainstem regions that neighbor upon spared-whisker projection fields. However, SO and $\mathrm{PO}$ patch enlargement proceeded as in animals whose ganglion cells were not rescued (Fig. 15). Significant increases in transverse patch areas were demonstrated on PND3, PND5, and PND7, and these increases did not differ in time course or extent from those exhibited in animals not receiving exogenous NGF (compare with data in Fig. 4). 

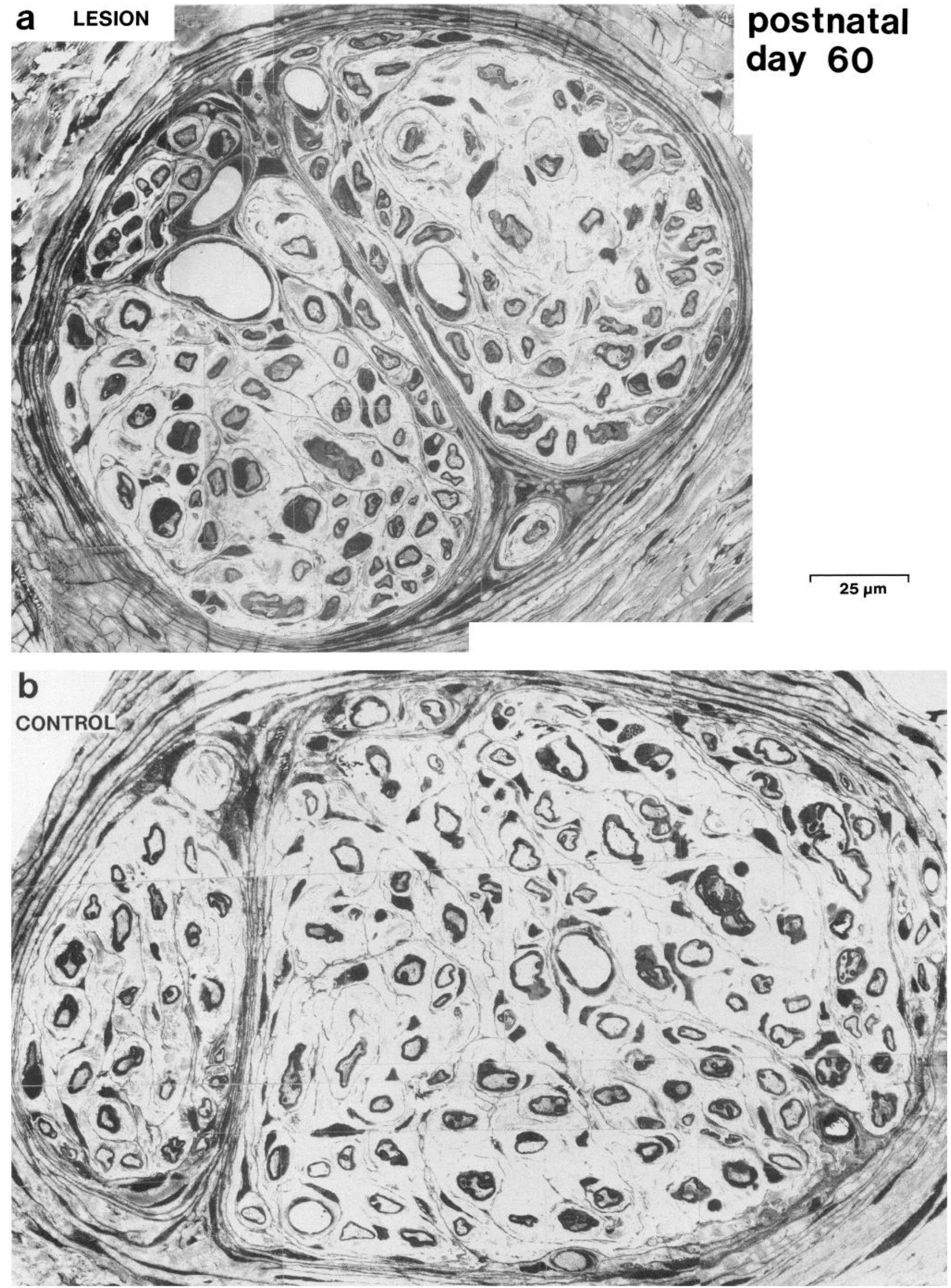

Figure 6. Low-magnification montages of electron micrographs taken from the deep vibrissal nerve in a PND60 SO follicle ipsilateral (a) and contralateral $(b)$ to the neonatally transected infraorbital nerve. On the lesion side, there are 133 myelinated and 97 unmyelinated fibers; on the control side, there are 127 myelinated and 97 unmyelinated fibers. 

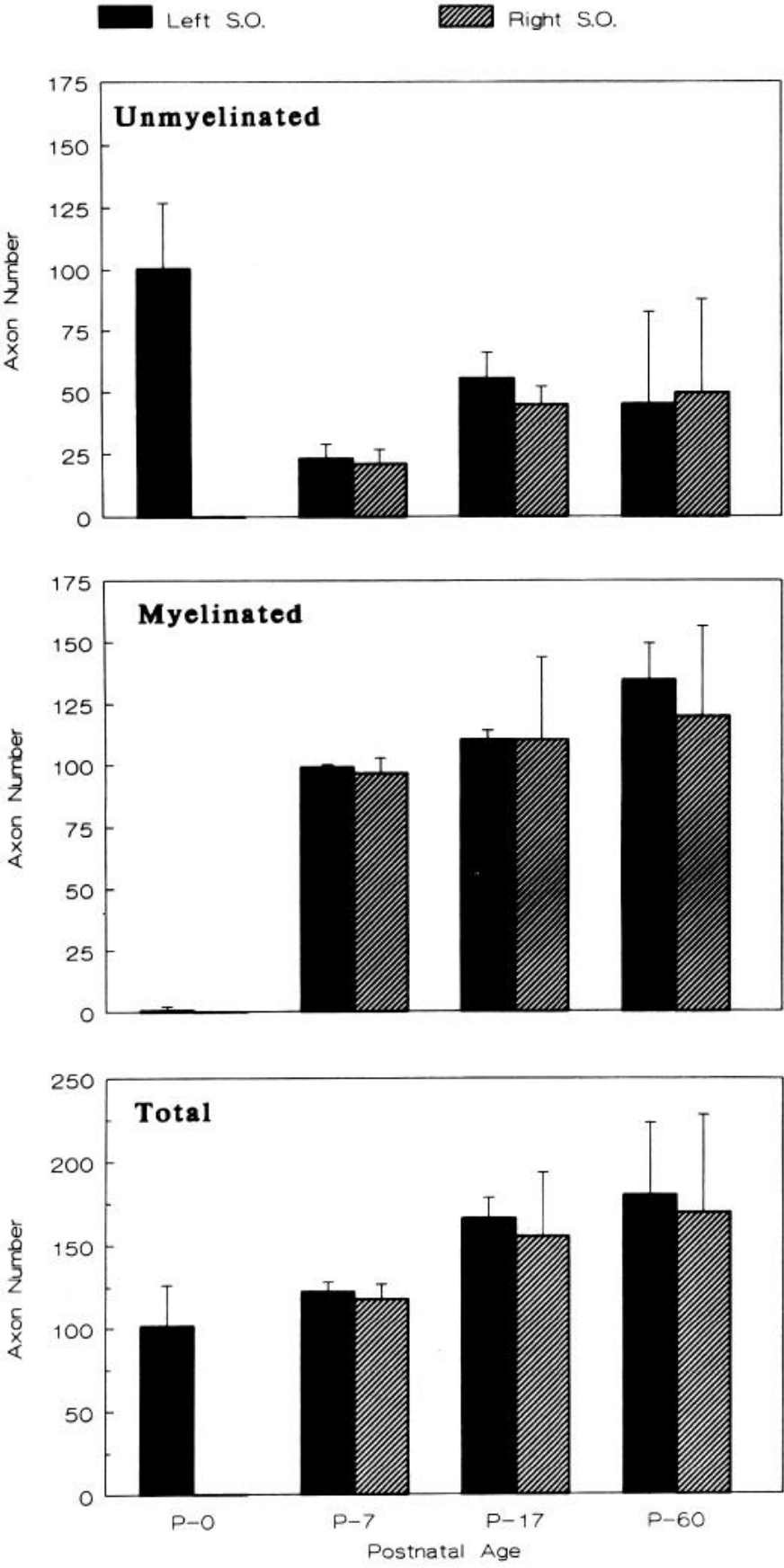

Figure 7. Mean $( \pm \mathrm{SD})$ numbers of axons in the experimental left versus control right deep vibrissal nerves from SO follicles on the day of $(P-O)$, and after (PND7, PND17, PND60), left infraorbital nerve section. The bottom panel shows the summed data comprising the top two panels. Only left follicles were examined on $P-0$. No left:right difference reached statistical significance at any age.
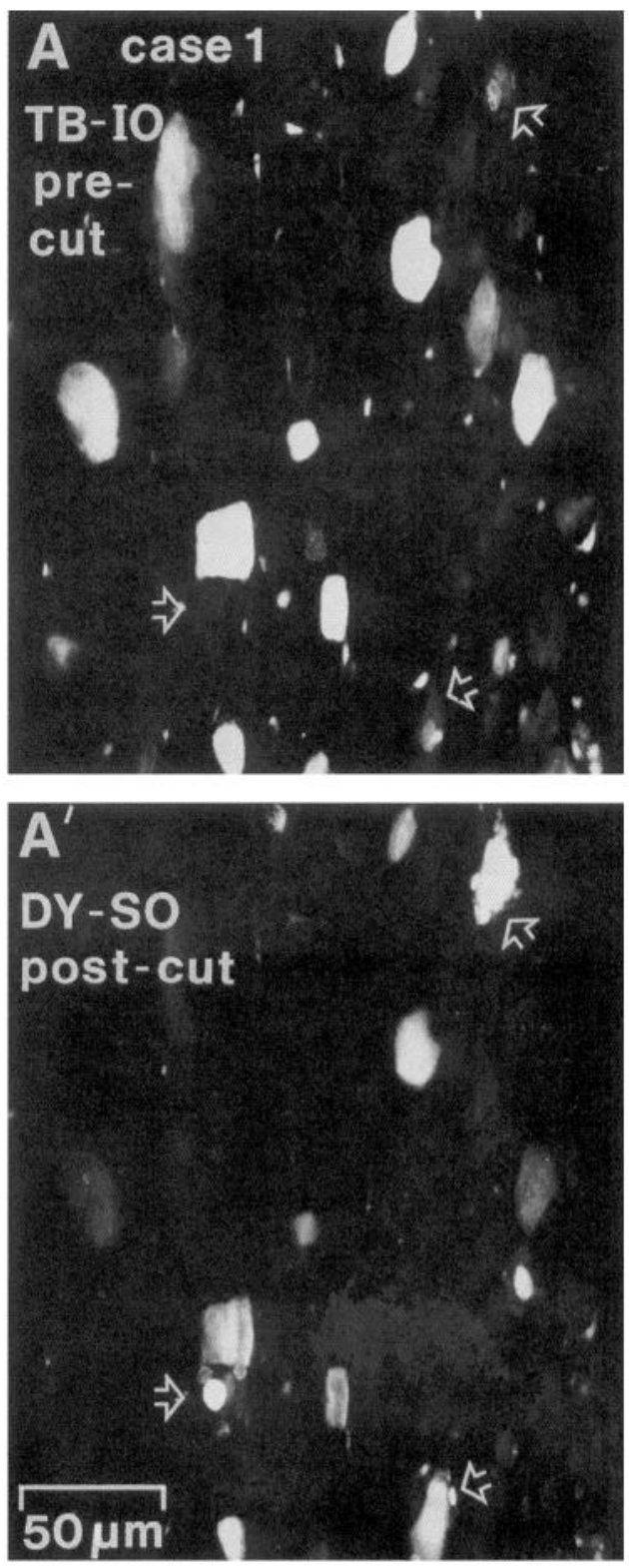

Figure 8. Retrograde double-labeling experiments failed to reveal even one infraorbital $(I O)$ ganglion cell whose axon regenerated into the $\mathrm{SO}$ nerve. Epifluorescent illumination at two different wavelengths is shown for one focal plane through the $\mathrm{V}$ ganglion whose infraorbital nerve was cut at birth. $A$ shows intensely fluorescent, true blue (TB)-positive ganglion cells that were labeled from the infraorbital nerve prior to nerve section, and weak "shine-through" in a second population of diamidino yellow $(D Y)$-positive cells that were labeled from the ipsilateral SO follicles in adulthood (arrows). $A^{\prime}$ is taken from the regions corresponding to $A$, except under yellow illumination. Intensely fluorescent diamidino yellow-labeled cells can be seen (arrows), as well as "shine-through" in a second group of true blue-labeled cells. Note that no cells are double labeled.

Figure 9. Infraorbital nerve blockade from birth with TTX failed to produce SO and PO patch enlargement in SpVi. Cytochrome oxidase-stained, transverse sections from representative cases killed on PND3, PND5, and PND7 are shown from the experimental left and control right sides at the level of the obex. Bupivicaine injections into the mystacial pad also failed to mimic the effects of nerve section upon SO and PO patches in SpVi (not illustrated). 

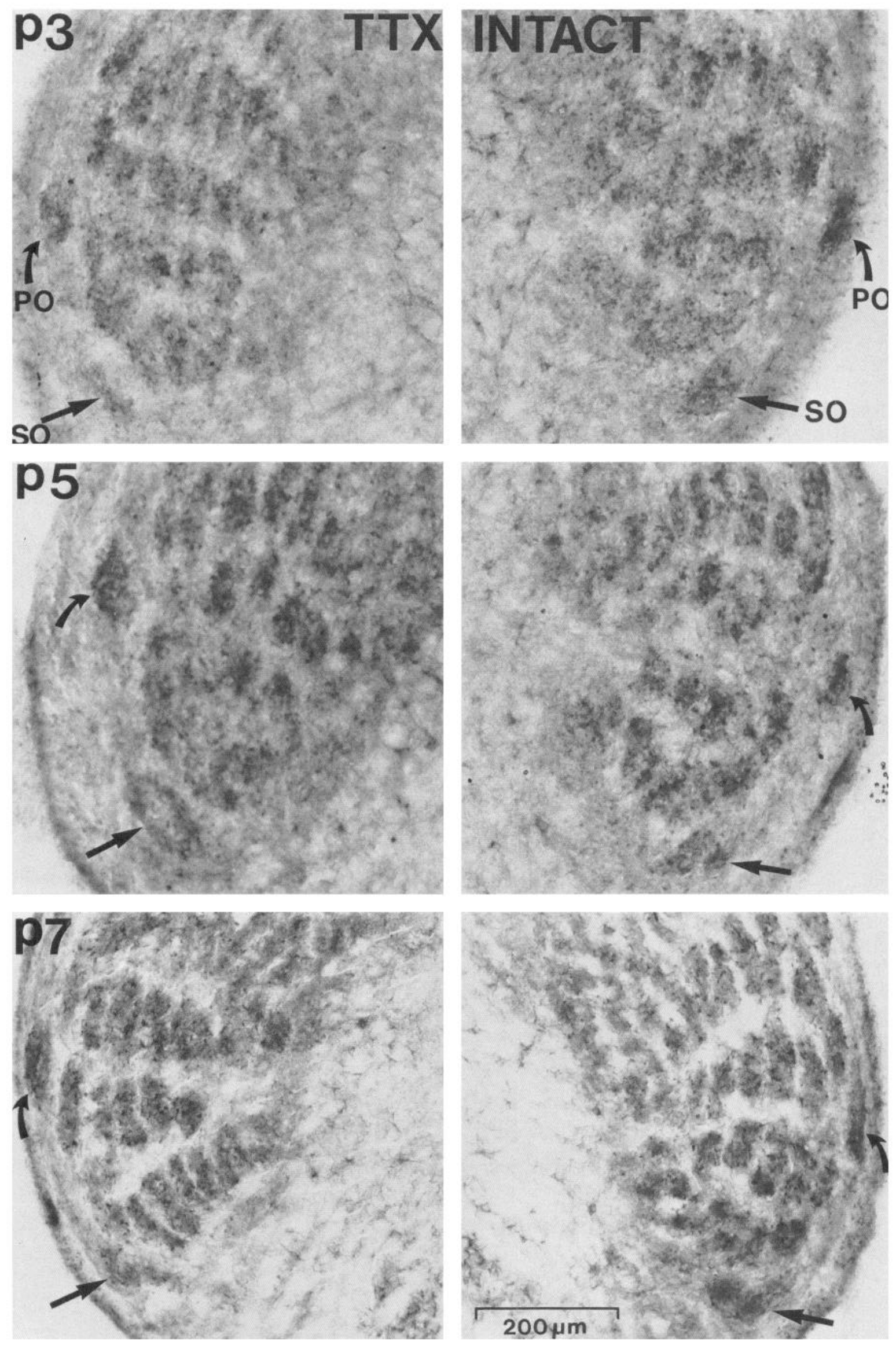


\section{IO Nerve Block}

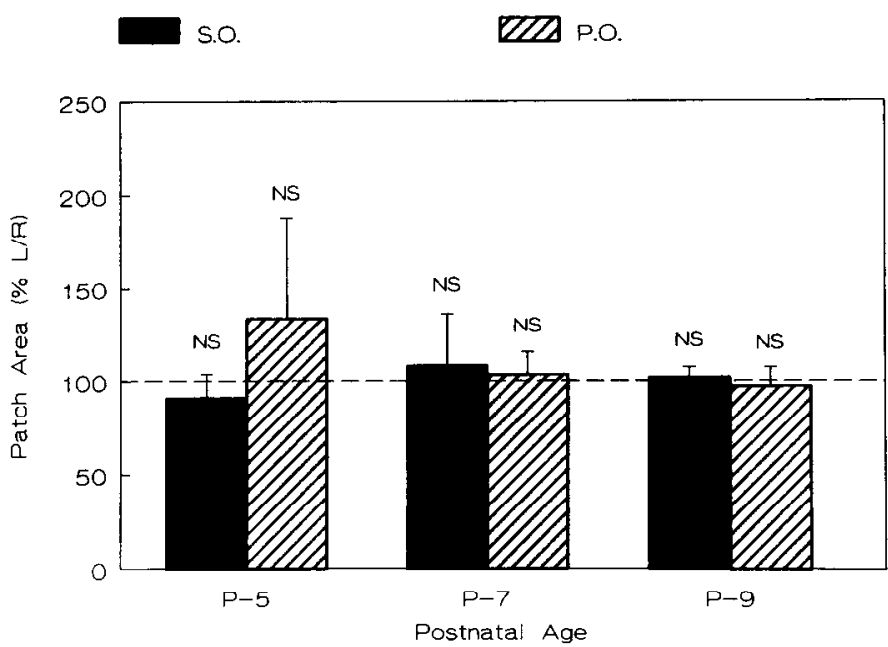

Figure 10. Transverse areal measurements of the cytochrome oxidasestained $\mathrm{SO}$ and $\mathrm{PO}$ patches in $\mathrm{SpVi}$ from all cases receiving infraorbital nerve block from birth with TTX or bupivicaine on the left side, relative to those on the control right side. Lesion-induced increases were not significant (NS) for any age group. Data were reduced to a median left: right percentage from multiple sections within single cases; the means \pm SDs of these values from all cases are shown here, with $100 \%$ indicating no difference from control.

Thus, enlarged spared-whisker projections were also seen when many axotomized ganglion cells and their central projections were preserved by exogenous trophic support.

\section{Discussion}

The present study used one of the more robust, rapid, and replicable consequences of neonatal infraorbital nerve injury, namely, the enlarged central representations of noninfraorbital whiskers, to address possible mechanisms underlying injuryinduced reorganization in the developing $\mathrm{V}$ system. Our results suggest that central arbor expansion in spared-whisker primary afferents underlies prior and present reports of enlarged (1) SO and PO cytochrome oxidase patches, (2) PO primary afferent projections (Waite and de Permentier, 1991), and (3) V brainstem areas containing cells responsive to $\mathrm{SO}$ and $\mathrm{PO}$ whiskers (Waite, 1984; Jacquin, 1989), whereas peripheral reorganization docs not appear to have a role. The actual injury-related signal(s) that induces arbor expansion remains to be elucidated, although our data suggest that such a signal(s) is not related to injuryinduced impulse activity alterations or ganglion cell death.

\section{Technical limitations}

First, our exclusive use of cytochrome oxidase to mark sparedwhisker representations, while necessary because of the difficulties in accurately tracing single whisker projections in young rats, is not without shortcomings. It is now recognized that cytochrome oxidase staining occurs predominantly in somadendritic mitochondria (e.g., Carroll and Wong-Riley, 1984; Woolsey, 1990; Chiaia et al., 1991). Therefore, our chosen marker reveals primarily second-order somatotopy and the conclusions drawn here regarding primary afferent termination patterns are inferred based on present and prior indications of an accurate spatial correspondence between single whisker cytochrome patches and matching whisker projection patterns (e.g., Jensen and Killackey, 1987; Chiaia et al., 1992). Additional justification for this strategy comes from the recent study of Waite and de Permentier (1991), where anterograde tracing methods were used to show similar increases in the transverse areas subtended by $\mathrm{PO}$ whisker primary afferent projections to $\mathrm{SpVi}$ in the adult rat.

Second, in testing the possibility of a peripheral supernumerary axon contribution to central patch enlargement, only fibers in the deep vibrissal nerves were considered. Inasmuch as superficial vibrissal nerve fibers also project to $\mathrm{SpVi}$ (Arvidsson and Rice, 1991 ; P. M. E. Waite and M. F. Jacquin, unpublished data), it is possible that their numbers are increased in spared follicles following infraorbital nerve injury. The relatively small number of superficial nerve fibers per follicle in normal animals (Waite and Jacquin, 1992) and their sparse projections to SpVi (Arvidsson and Rice, 1991), however, obviate against their contributing significantly to the presently described phenomenon.

Third, there are limitations inherent to using nerve block paradigms to "mimic" the consequences of neonatal nerve section in testing for possible activity-based competitive substrates for injury-induced reorganization. Insofar as nerve section almost certainly eliminates whisker deflection-evoked impulses during most of the postoperative intervals examined in this report ( $10 \mathrm{~d}$ maximum), it is likely that the nerve block mimics the nerve cut condition with respect to alterations in stimulusevoked impulse activity. However, our conclusion that injuryinduced changes in infraorbital impulse activity are not necessary for spared-whisker patch enlargement must be tempered by the likelihood that some axotomized cells exhibit injury- or spontaneous-discharges during the postoperative intervals considered here. Thus, some yet-to-be-determined injury-induced discharges conceivably could be responsible for the anatomical changes described here.

Fourth, there are limitations inherent to our use of a cell/fiber rescuing method to determine whether infraorbital inputs to SpVi constrain the arbor dimensions of noninfraorbital inputs during development. While available data suggest that exogenous trophic support rescues infraorbital ganglion cells (Henderson et al., 1993) and their central projections from injury-induced degeneration, at least beyond the time at which spared-whisker patches exhibit a plastic response, more "subtle" aspects of the morphologies of infraorbital axons that were not examined could conceivably impact upon the growth of noninfraorbital collaterals. For example, although DiI labeling experiments indicate that some rescued ganglion cells maintain a central projection

Figure 11. Photomicrographs of HRP-stained collaterals in the left SpVi from two primary afferents that responded to SO whisker deflection The fiber shown in the left panels is from an adult subjected to left infraorbital nerve section at birth. It responded phasically to sustained deflection of the caudal $S O$ whisker and $0.35 \mathrm{mscc}$ after left $\mathrm{V}$ ganglion shocks. After impaling the axon, as evidenced by a $60 \mathrm{mV}$ resting potential, HRP was ejected for $5 \mathrm{~min}$ with $10 \mathrm{nA}$ positive pulses. The fiber shown on the right is from a normal adult. It responded phasically to sustained deflection of the caudal SO whisker and $0.25 \mathrm{msec}$ after $\mathrm{V}$ ganglion shocks. After a $70 \mathrm{mV}$ resting potential was obtained, HRP was ejected for 10 min with $10 \mathrm{nA}$ pulses. Open arrows indicate the parent fiber in the V spinal tract. Straight solid arrows indicate unusual excursions of secondary collaterals from the region of the primary arbor focus. Curved arrows denote secondary collaterals curving back toward the primary arbor focus. 


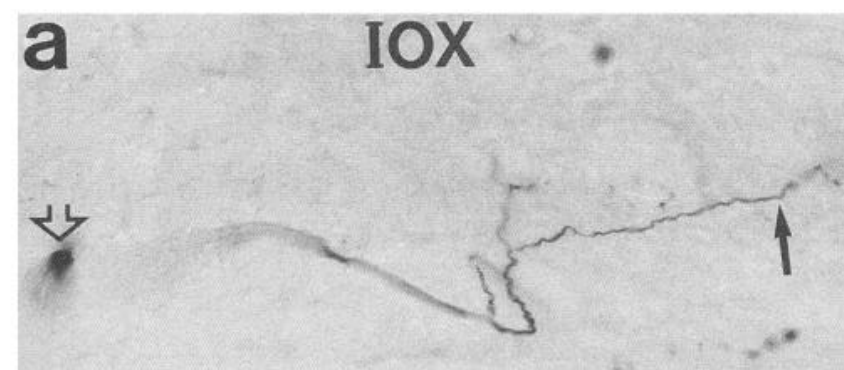

$100 \mu \mathrm{m}$
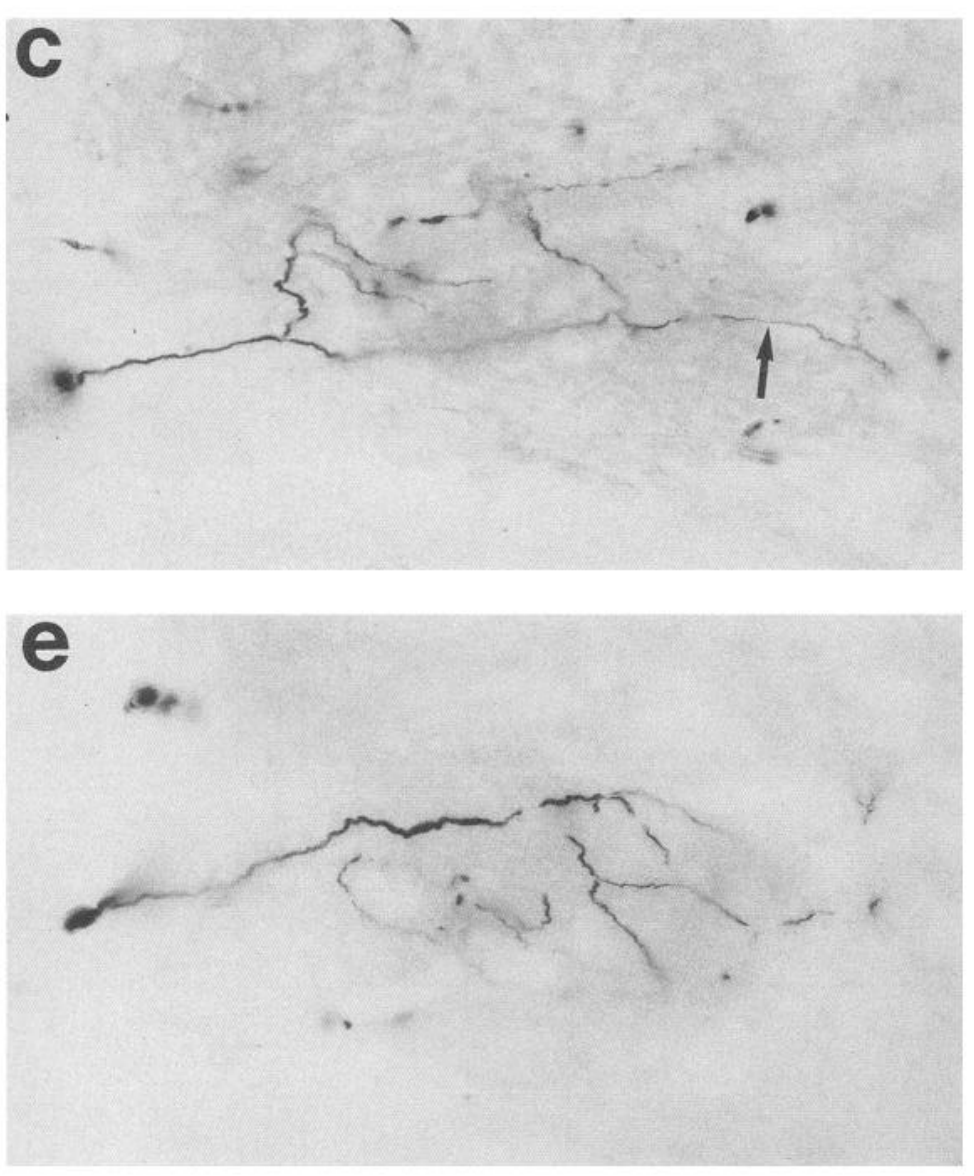

\section{g}

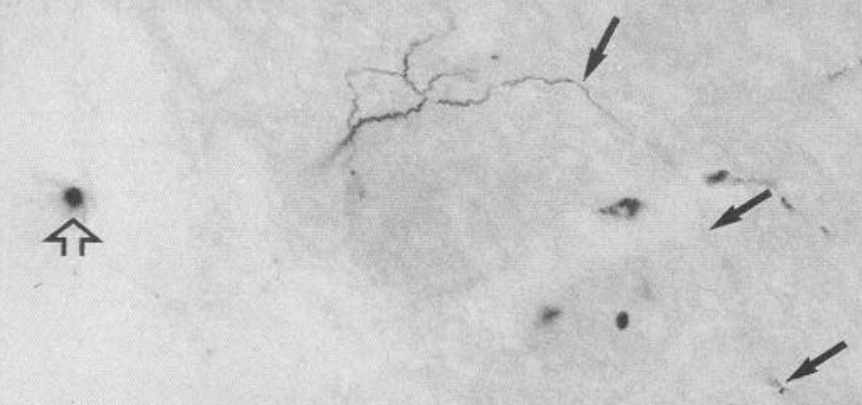

\#404L b INTACT

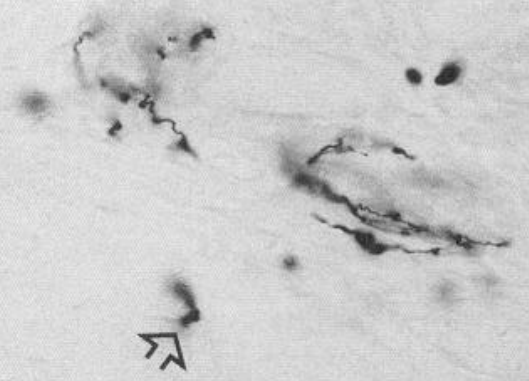

d

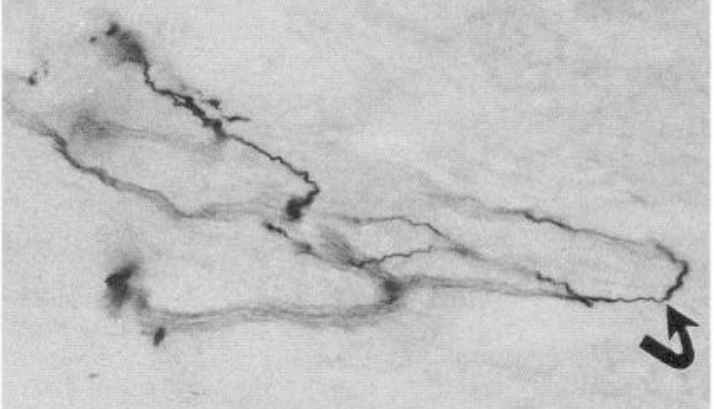

f
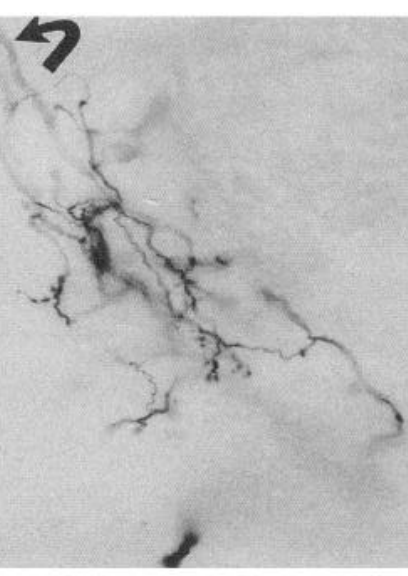

h

\# R3L

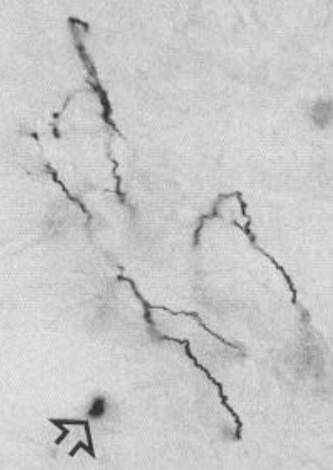




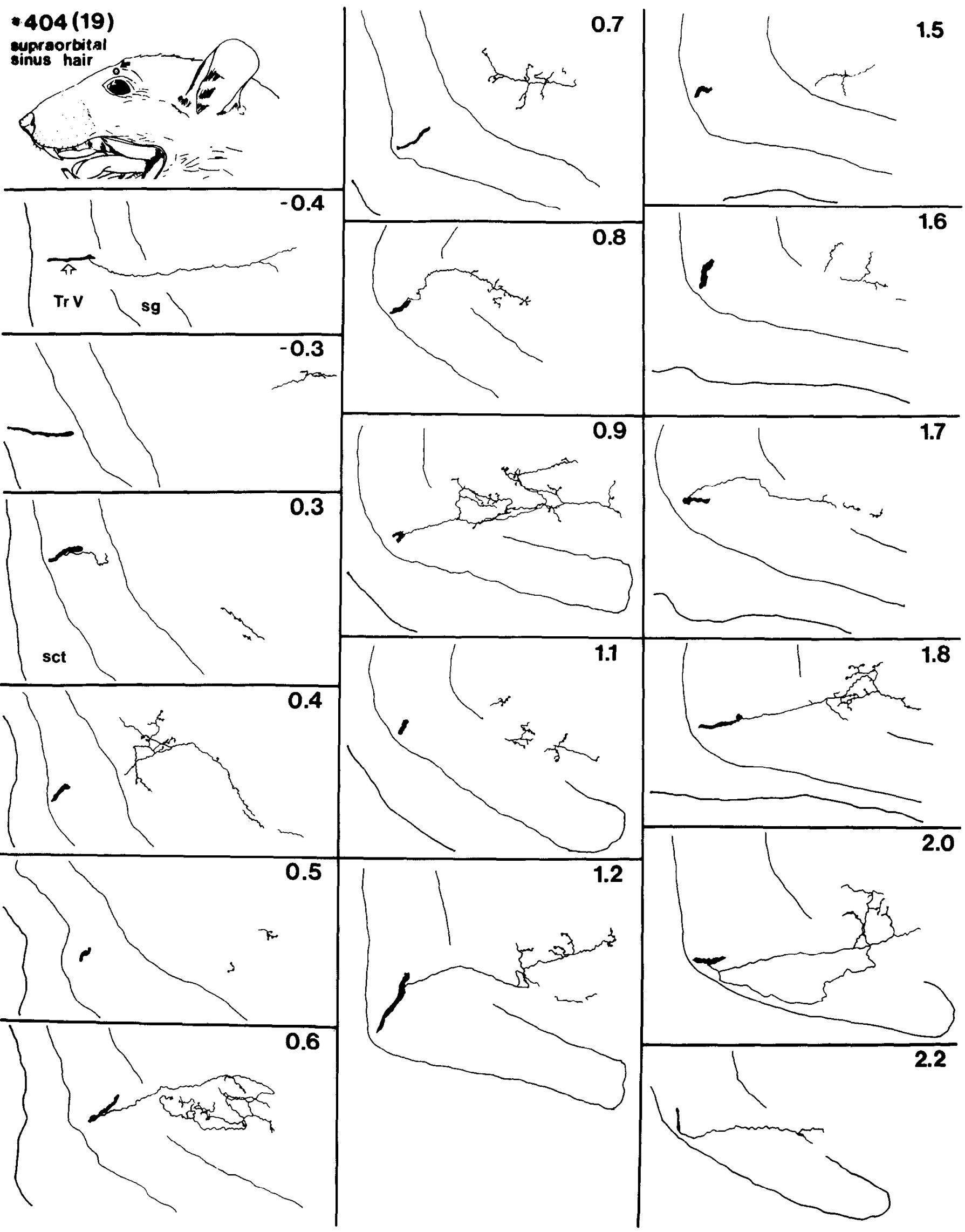

Figure 12. Serial reconstruction of the experimental SO primary afferent illustrated in the left half of Figure 11 whose receptive field is indicated on the drawing (top left). Low-magnification drawings of this fiber's central processes in $100 \mu \mathrm{m}$ transverse sections through the left SpVi are staged 

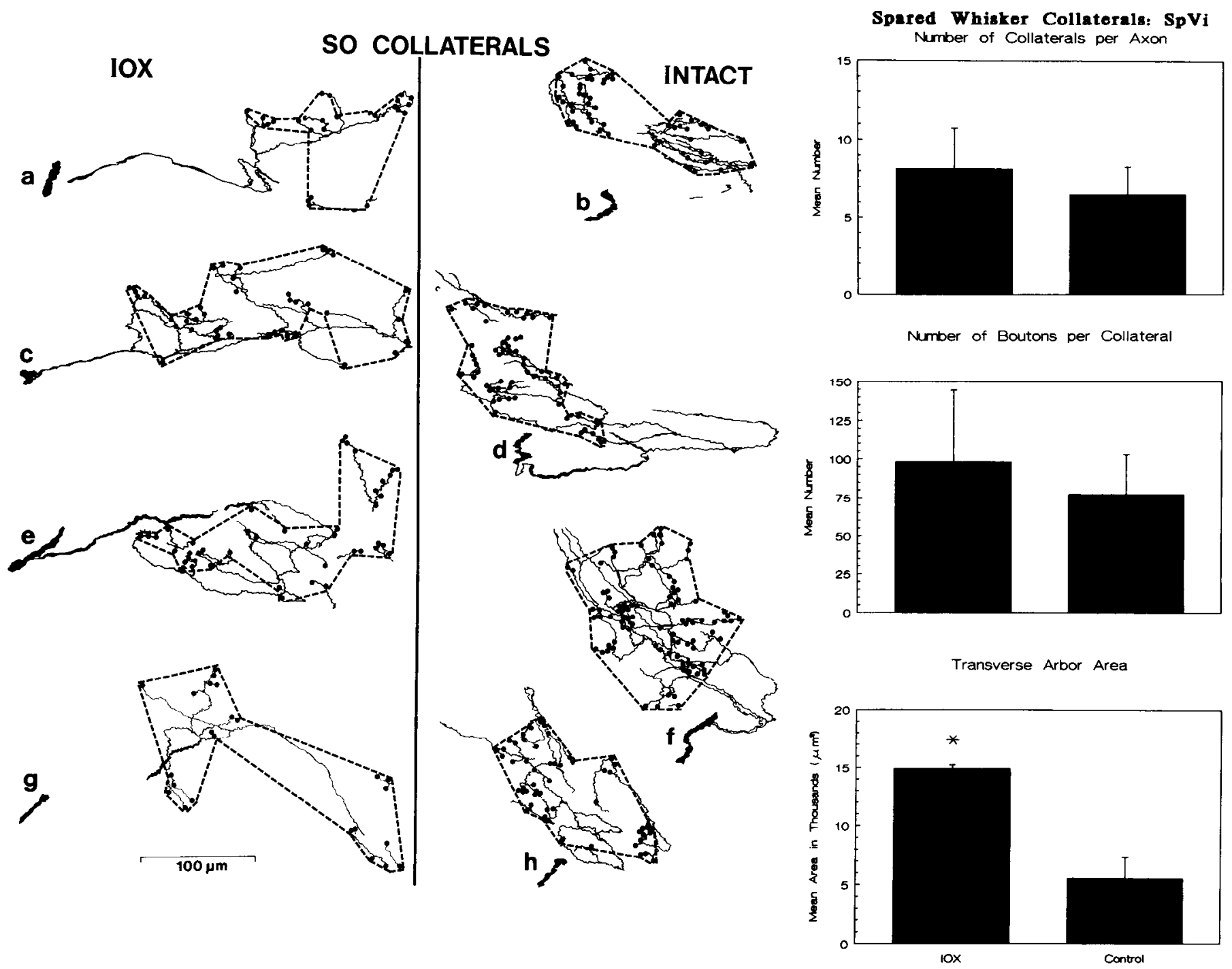

Figure 13. Left, Examples of arbor envelopes (broken lines) used to derive a quantitative estimate of transverse arbor areas in experimental (IOX) and control (INTACT) primary afferent collaterals. Arbor envelopes are drawn on reconstructions of selected SpVi collaterals that are also illustrated in micrograph format in Figure 11. Labeled boutons have been enlarged for illustrative purposes. See Materials and Methods for the criteria that were followed in deriving these arbor outlines. Each collateral is identified separately by a letter placed next to that collateral's parent fiber in the $\mathrm{V}$ spinal tract. Right, Morphometric analyses of all of the collaterals in SpVi from $10 \mathrm{~V}$ primary afferents responsive to SO or PO whisker deflection in adults with infraorbital nerve section at birth $(I O X)$ versus 10 functionally equivalent fibers from normal adults (Control). SDs are shown. *, statistically significant difference.

to the $\mathrm{V}$ brainstem complex, such bulk transport data do not permit a determination of whether all rescued cells project to $\mathrm{SpVi}$, nor do they permit an assessment of the morphology of rescued fibers. Some infraorbital collaterals may be in various degenerative phases, or terminals may have been eliminated, thus altering a component(s) of their anatomy that may impact upon the development of neighboring spared-whisker collaterals. Because axotomized collaterals were not examined at this level, our approach must therefore be considered but a first step in addressing the issue of whether neighboring fibers serve to constrain arbor development.
Fifth, our use of SpVi as a model may preclude conclusions pertaining to subcortical bases for cortical plasticity, insofar as $\mathrm{V}$ nucleus principalis is the necessary $\mathrm{V}$ brainstem component for barrel development (Killackey and Fleming, 1985). While this does limit the power of the conclusions drawn below, in every aspect examined to date, principalis and SpVi exhibit nearly identical responses to infraorbital injury (e.g., Woolsey, 1990; Waite and de Permentier, 1991). It is therefore likely that similar rules govern plasticity in $\mathrm{SpVi}$ and other $\mathrm{V}$ brainstem subnuclei. Therefore, the argument can be made that the present data are applicable to emerging formulations of subcortical bases

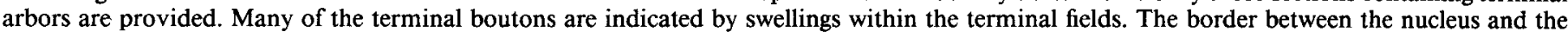

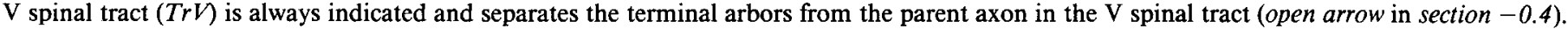
$s g$, substantia gelatinosa; $s c t$, spinocerebellar tract. Compare with control fiber reconstructed in Figure 9 of Jacquin et al. (1986). 

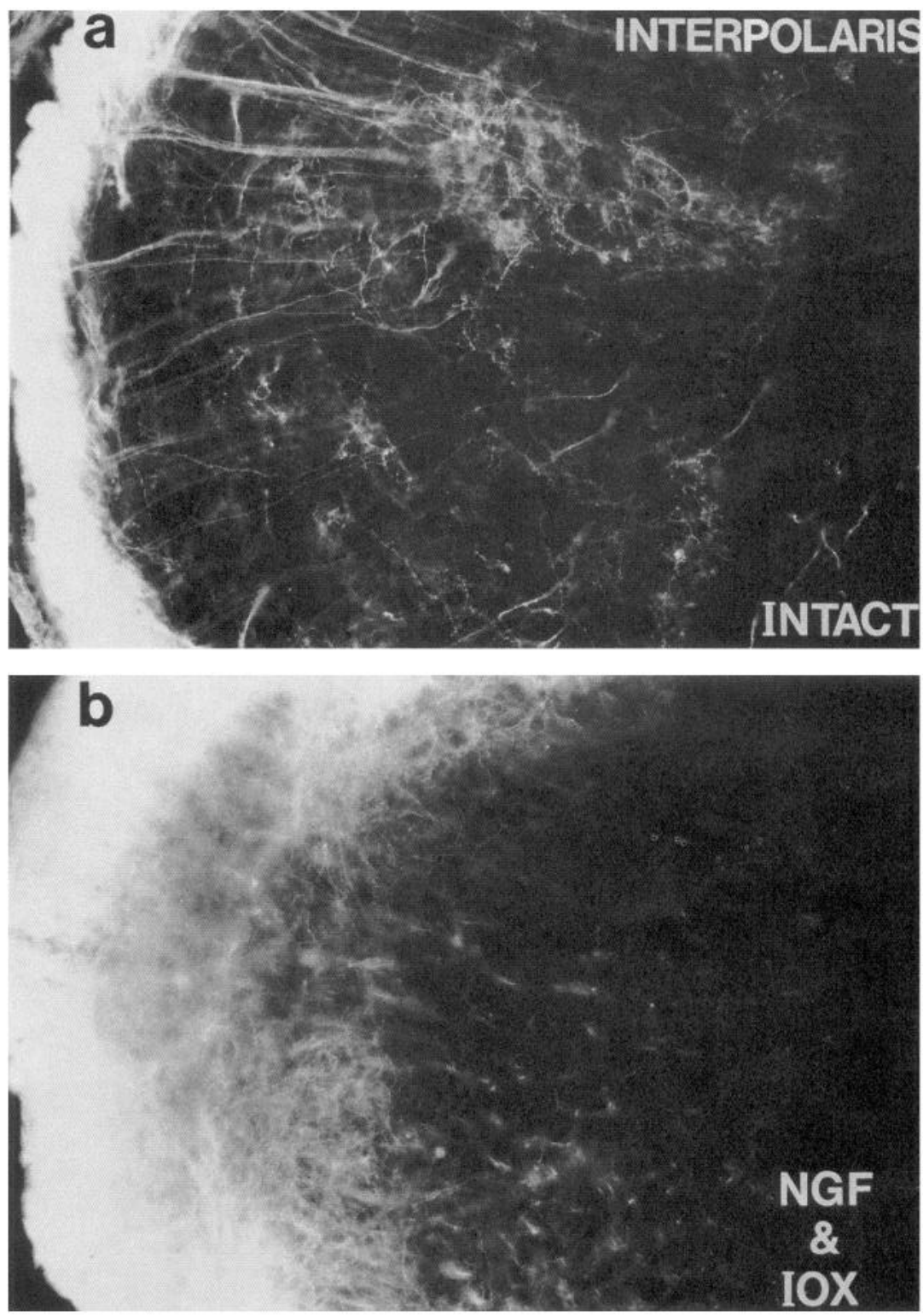

Figure 14. DiI-stained projections of the $\mathrm{V}$ nerve to $\mathrm{SpVi}$ in three rats killed on PND5. The first received no treatment $(I N T A C T, a)$; the second received exogenous NGF injections prior to and after infraorbital nerve section at birth $(N G F \& I O X, b)$; the third sustained infraorbital nerve section at birth without NGF $(c)$. Note that the NGF-treated case displays more substantial projections to $\mathrm{SpVi}$ than the case not receiving NGF. Epifluorescent rhodamine excitation; $100 \mu \mathrm{m}$ transverse sections.

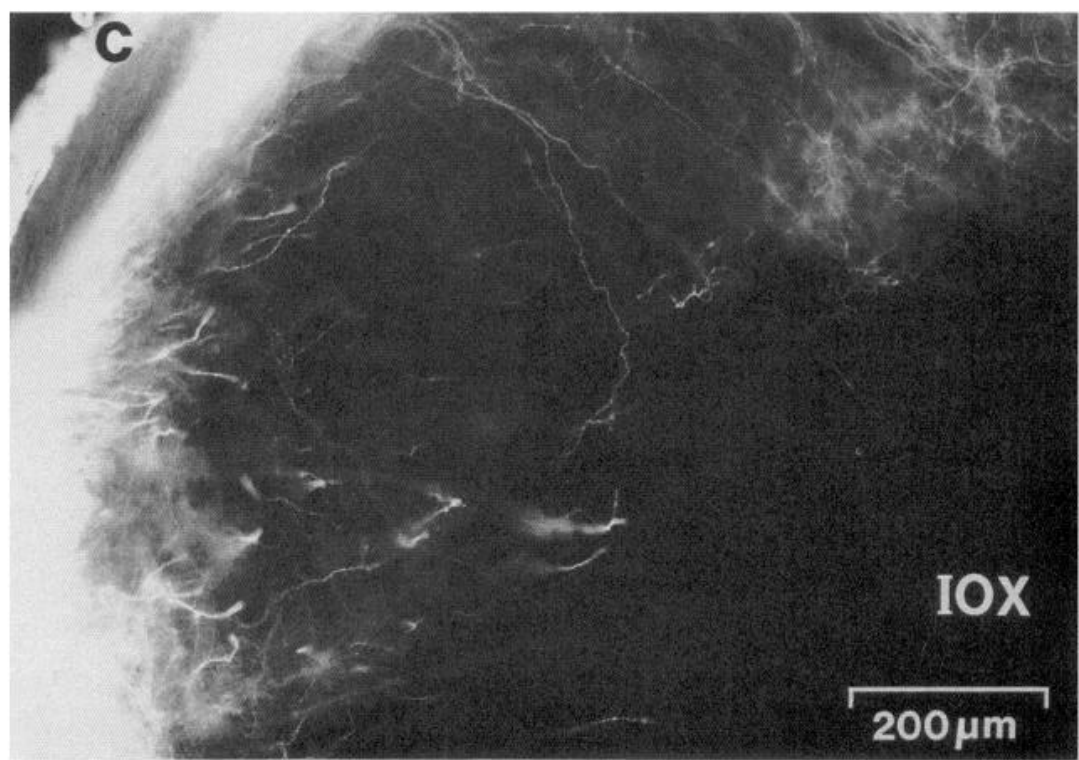




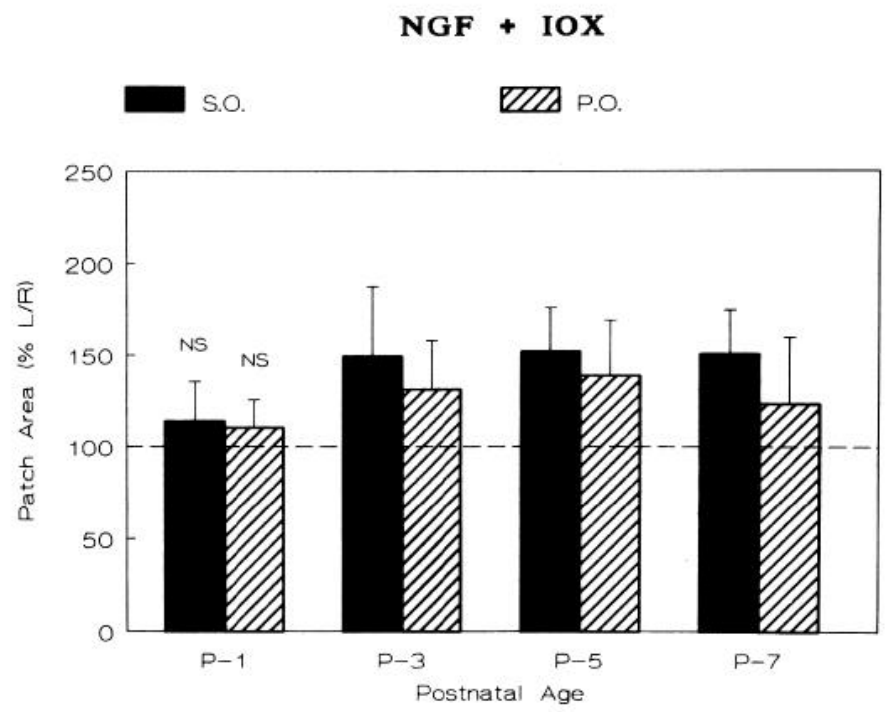

Figure 15. Top, Transverse areal measurements of the cytochrome oxidase-stained SO and PO patches in $\mathrm{SpVi}$ from all cases receiving NGF injections prior to and every day after infraorbital nerve section at birth on the left side, relative to those on the control right side. Lesioninduced increases were not significant (NS) only in the PND1 age group. Data were reduced to a median left:right percentage from multiple sections within single cases; the means \pm SDs of these values from all cases are shown here, with $100 \%$ indicating no difference from control. See Figure 4 for comparable data from cases not receiving NGF injections. Bottom, Cytochrome oxidase-stained transverse section from one case killed on PND5 showing the experimental left and control right sides. NGF injections prior to and after infraorbital nerve section at birth failed to prevent SO (straight arrows) and PO (curved arrows) patch enlargement in SpVi.

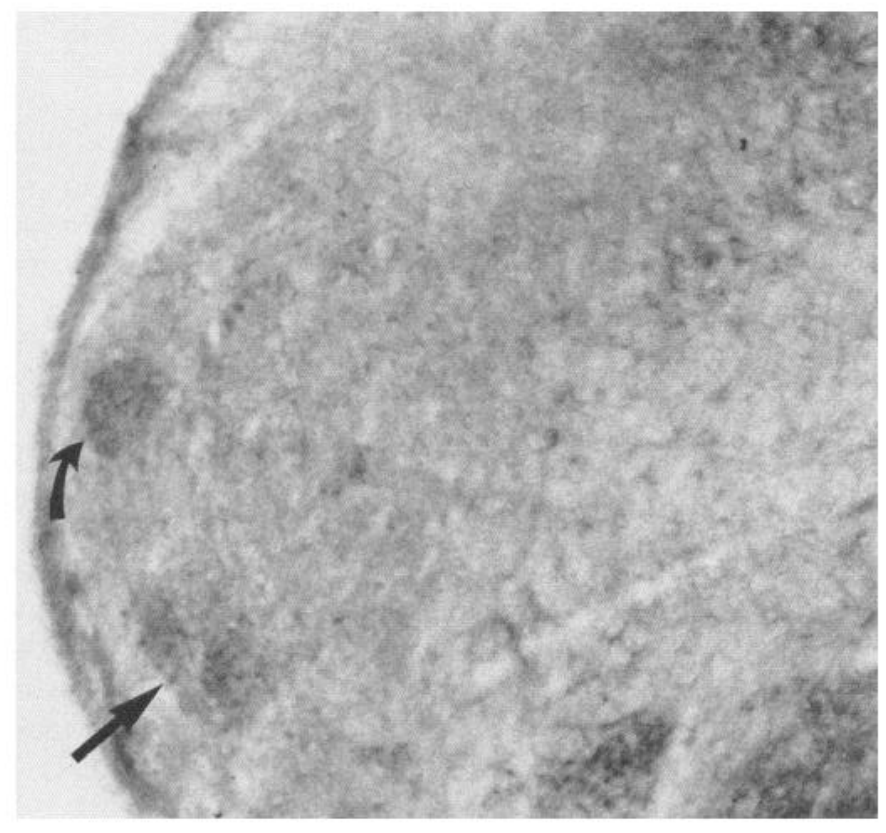

for higher-order plasticity (e.g., Killackey et al., 1990: Rhoades et al., 1990; Woolsey, 1990).

\section{Spared-whisker plasticity: the phenomenon}

The present results extend those of Renehan et al. (1989), who demonstrated significantly enlarged transverse areas in $\mathrm{SpVi}$ collaterals from infraorbital whisker primary afferents that had survived infraorbital axotomy at birth $\left(12,940 \mu \mathrm{m}^{2}\right)$, relative to normal infraorbital afferents $\left(6130 \mu \mathrm{m}^{2}\right)$. These values correspond well with the transverse areas of noninfraorbital whisker afferents provided in the present report $\left(14,879 \mu \mathrm{m}^{2}\right.$ experimental and $5527 \mu \mathrm{m}^{2}$ normal). The present study and that of Renehan et al. also indicate that the total number of SpVi collaterals given off by infraorbital and noninfraorbital afferents is unaffected by neonatal nerve section. It would therefore appear that similar principles guide the response of all surviving whisker primary afferents to neonatal infraorbital injury, irrespective of whether the fibers were included in the axotomized population.

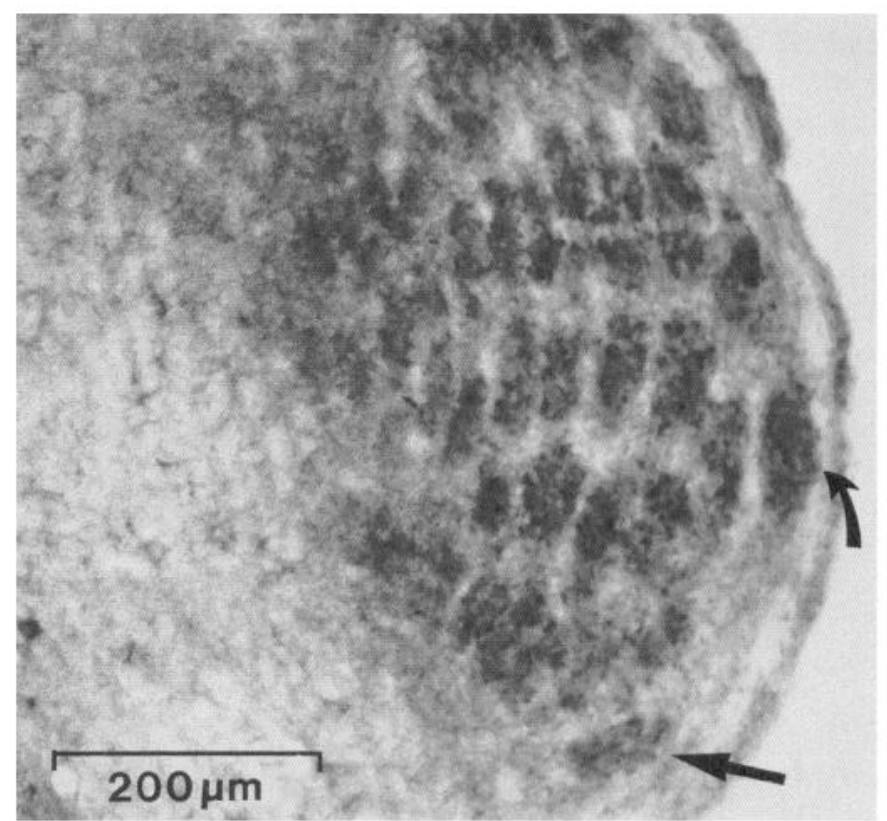

Our results also confirm and extend the findings of Waite and de Permentier (1991), who used bulk-labeling methods to demonstrate an enlargement of the central projections of the $P O$ whisker nerve in adult rats subjected to infraorbital nerve section at birth. The present finding of cytochrome oxidase patch enlargement within 1.5-3 d after the lesion strongly suggests that $\mathrm{SO}$ and $\mathrm{PO}$ projections to $\mathrm{SpVi}$ undergo a rapid remodeling in response to infraorbital injury. Waite and de Permentier also reported a less robust, though significant, enlargement of the PO nerve projection when the infraorbital nerve was sectioned on PND7, but not when the nerve was cut in adulthood. These data strongly suggest that spared-whisker patch enlargement occurs only during a critical or sensitive period in development.

Given the above, it is difficult to reconcile the present findings with prior reports (Belford and Killackey, 1980; Durham and Woolsey, 1984) that cauterizing specific rows of whisker follicles at birth did not result in an enlargement of cytochrome patches representing adjacent, intact follicles. These authors viewed this negative result as evidence against a role for interaxonal com- 
petition in shaping the development of whisker primary afferent arbors. On the other hand, data reviewed here suggest that SO and PO whisker projections to SpVi do enlarge after complete infraorbital denervation at birth. Perhaps the differing results reflect technical differences in the two preparations, notably, the fact that nerve section affects a much broader population of axons than follicle cauterization. Alternatively, different whiskers may have different critical periods during which arbor expansion can be induced in their associated central axons. The findings of Chiaia et al. (1992) suggest that both explanations may be tenable. They reported that cauterization of selected mystacial whisker follicles in rat fetuses on embryonic days 1518 did result in significant increases in the average area of the remaining cytochrome patches, whereas similar lesions inflicted during later fetal periods or at birth did not produce changes in spared patch sizes. Thus, the critical period(s) for infraorbital nerve section-induced, nonmystacial, arbor expansion probably extends later in life than that of cautery-induced, mystacial arbor expansion.

The present results, in conjunction with prior work by Erzurumlu and Killackey (1983), Henderson et al. (1991), and Chiaia et al. (1992), also strongly suggest that overlap of terminal fields between mystacial and nonmystacial afferents is not prerequisite for injury-induced expansion of nonmystacial whisker arbors into mystacial whisker territory. The above-cited studies clearly indicate that a normally segmented and somatotopic map of the periphery can be discerned with anterograde tracing and metabolic staining methods at the time of birth in rats. Moreover, we have demonstrated a progressive, injury-induced enlargement in the SO and $\mathrm{PO}$ patches over the first few postnatal days. Both of these observations argue against the possibility that spared-whisker plasticity in this paradigm reflects the maintenance of an immature and overlapping projection pattern at the time of the lesion.

\section{Spared-whisker plasticity: the mechanism(s)}

The present study has revealed an anatomical substrate for prior reports of expanded regions of SpVi devoted to the SO and PO whiskers, following infraorbital nerve section at birth (Waite, 1984; Jacquin, 1989). This finding is analogous to a prior demonstration (Jacquin et al., 1989) that neonatal deafferentation induces novel cervical primary afferent projections to $\mathrm{SpVi}$ that are reflected in the receptive fields of $\mathrm{SpVi}$ cells. The major thrust of the present study was, however, an attempt to elucidate the necessary and sufficient conditions for such plasticity. We were successful in rejecting a number of candidate mechanisms with compelling precedents in the developing $V$ as well as other neuronal systems.

The possibility that a greater than adultlike number of axons are present in the SO whisker follicle at birth, and that such supernumerary axons are in some way "preserved" by infraorbital injury, was tested, and the results were negative. Analysis of SO deep vibrissal nerves from the control side suggests that average axon numbers normally increase from 101 at birth, to 118,156 , and 170 on PND7, PND17, and PND60, respectively. These data suggest that fibers are added, rather than eliminated, during postnatal maturation of the SO whisker follicle. This conclusion is inconsistent with a prior report (Crissman et al., 1991) of adultlike numbers of fibers in newborn mystacial vibrissal nerves, as well as many other reports of supernumerary fibers in the $\mathrm{V}$ nerve that are lost during pre- and postnatal development (e.g., Davies and Lumsden, 1984; Renehan and
Rhoades, 1984; O'Connor and van der Kooy, 1986). The basis for this discrepancy is currently unclear.

The present study also failed to reveal changes in the number of axons in the SO deep vibrissal nerve ipsilateral to the lesion at PND7, PND17, and PND60. Our negative results argue against the possibility that an injury-induced change in $\mathrm{SO}$ axon number contributes to spared-whisker plasticity. A similar conclusion was drawn by Chiaia et al. (1992), who found that cauterization of selected follicles in fetal rats produced enlarged spared-whisker cytochrome patches in SpVi, without accompanying changes in myelinated axon numbers in the spared whiskers. These results and those discussed below point toward the absence of a peripheral contribution to spared-whisker plasticity. It should be noted, however, that a recent report from Waite and colleagues (Williams et al., 1992) provides electron microscopic evidence for an increase in the number of unmyelinated, but not myelinated, axons in the deep vibrissal nerve supplying the adult PO follicle after infraorbital nerve section at birth. Insofar as unmyelinated axons project only sparsely to $\mathrm{SpVi}$ in normal perinatal and adult rats, as well as adults with infraorbital injury at birth (Bennett-Clarke and Chiaia, 1992), it is unlikely that these "extra" fibers contribute to the PO patch enlargement reported here and previously (Waite and de Permentier, 1991). As suggested by Williams et al. (1992), the increased axon numbers observed in the $\mathrm{PO}$, as opposed to the $\mathrm{SO}$, follicles after infraorbital injury likely reflect the fact that the PO follicle, like the infraorbital nerve, is innervated by the maxillary nerve, whereas the SO follicle is innervated by the ophthalmic nerve.

Prior studies (Jacquin et al., 1986; Rhoades et al., 1987, 1991; Chiaia et al., 1988; Klein et al., 1988) indicate that most infraorbital ganglion cells do not regenerate to the same whisker that they projected to prior to the neonatal lesion. Moreover, Rhoades et al. (1987) have demonstrated that some axotomized ganglion cells regenerate through a completely different $\mathrm{V}$ division. Therefore, a possible explanation for the observed spared-whisker plasticity in SpVi is that some surviving infraorbital axons regenerate incorrectly through the $\mathrm{SO}$ nerve, thus resulting in both an SO and an infraorbital contribution to the "SO" patch in $\mathrm{SpVi}$. That is, an "SO" patch in SpVi may have become larger because it incorporated once-infraorbital axons. The above-described negative effect upon axon numbers in the SO nerve makes this possibility unlikely. Our retrograde double-labeling study provided a more direct test of this hypothesis, however. This experiment failed to reveal any indication of axotomized ganglion cells that regenerated their axons through the SO nerve. Thus, it is highly unlikely that regeneration errors contribute to spared-whisker plasticity in SpVi.

All of the above points toward a CNS consequence(s) of neonatal nerve injury as the basis for the rapid enlargement of brainstem patches representing the SO and PO whiskers. Our results indicate that spared axon collaterals arborize in a more widespread fashion in SpVi following infraorbital injury, making this the likely basis for patch enlargement. As discussed by Renehan et al. (1989), arbor expansion differs from collateral sprouting and we have no evidence for the latter making a contribution to this phenomenon, based upon the finding that collateral or bouton numbers did not change. Indeed, bouton density was decreased proportionate to the extent of the arbor expansion, suggesting that different mechanisms control the development of arbor area and bouton number. This concept is supported by the observation that chronic whisker trimming from birth, without a lesion, produces complementary effects 
upon arbor geometry, namely, decreased bouton numbers and unaffected arbor areas (M. F. Jacquin, B. G. Klein, and R. W. Rhoades, unpublished observations).

The actual signal serving to constrain arbors in normal development, or to permit arbor expansion by its injury-induced absence, remains to be elucidated. The results of infraorbital nerve block experiments provide an indication that the controlling signal is not engaged through an impulse activity-dependent competitive interaction. This is somewhat surprising, given the compelling evidence available for such a mechanism in developing visual, auditory, and motor systems (reviewed in Coleman, 1990). For example, when an eye, ear, or motor unit is placed at an activity-based competitive disadvantage via nerve block, spared fibers are known to establish unusual projections to targets where a remaining eye, ear, or motor unit are also represented. This simply did not occur in $\mathrm{SpVi}$ when infraorbital afferents were placed at an activity-based competitive disadvantage relative to $\mathrm{SO}$ and $\mathrm{PO}$ afferents. These data lend further fuel to the argument that pattern formation in the developing somatosensory system is governed by a different set of rules than those established to date in other sensory systems (see Henderson et al., 1992, for further discussion).

Of course, a mechanism based on competitive interactions between axons may indeed dictate how arbors develop. Unfortunately, at present we have no idea for what the axons might be competing, although our data suggest that it is not a trophic factor. It is possible that nerve section inflicted during a critical period prevents a given fiber's accessibility to a peripheral agent that offers it a competitive advantage. Alternatively, reactive changes in injured primary afferents might provide spared afferents with a central agent that is normally unavailable. What we currently do know, based upon the presently described cell/ fiber rescue experiments, is that for spared-whisker patch enlargement to occur, one need only "disconnect" the afferent axon from the mystacial pad. Injury-induced cell death and associated depletion of their central projections are not necessary to elicit spared-whisker afferent encroachment into SpVi regions "disconnected" from the periphery. As such, arbor expansion is probably not a "passive" process, but rather an active response to a yet-to-be-identified signal that, in effect, lifts constraints normally operating in development to shape whisker afferent arbor geometry.

\section{References}

Arvidsson J, Rice FL (1991) Central projections of primary sensory neurons innervating different parts of the vibrissae follicles and intervibrissal skin on the mystacial pad of the rat. J Comp Neurol 309: $1-16$.

Belford GR, Killackey HP (1979) Vibrissae representation in subcortical trigeminal centers of the neonatal rat. J Comp Neurol 183:305322.

Belford GR, Killackey HP (1980) The sensitive period in the development of the trigeminal system of the neonatal rat. J Comp Neurol 193:335-350.

Bennett-Clarke CA, Chiaia NL (1992) Normal development and effects of neonatal infraorbital nerve damage upon the innervation of the trigeminal brainstem complex by primary afferent fibers containing calcitonin gene-related peptide. J Comp Neurol 324:282-294.

Bocchini F, Angeletti PU (1969) The nerve growth factor: purification as a 30,000 molecular weight protein. Proc Natl Acad Sci USA 64: 787-794.

Carroll EW, Wong-Riley MTT (1984) Quantitative light and electron microscopic analysis of cytochrome oxidase rich zones in the striate cortex of the squirrel monkey. J Comp Neurol 222:1-17.

Chiaia NL, Hess PR, Rhoades RW (1987) Preventing regeneration of infraorbital axons does not alter the ganglionic or transganglionic consequences of neonatal transection of this trigeminal branch. Dev Brain Res 36:75-88.

Chiaia NL, Allen Z, Carlson E, Macdonald G, Rhoades RW (1988) Neonatal infraorbital nerve transection in rat results in peripheral trigeminal sprouting. J Comp Neurol 274:101-114.

Chiaia NL, Bcnnctt-Clarke CA, Rhoades RW (1991) Effects of cortical and thalamic lesions upon primary afferent terminations, distributions of projection neurons, and the cytochrome oxidase pattern in the trigeminal brainstem complex. J Comp Neurol 303:300-316.

Chiaia NL, Bennett-Clarke CA, Eck M, White FA, Crissman RS, Rhoades RW (1992) Evidence for prenatal competition among the central arbors of trigeminal primary afferent neurons. J Neurosci 12:62-76.

Coggeshall RE (1992) A consideration of neural counting methods. Trends Neurosci 15:9-13.

Coggeshall RE, La Forte R, Klein CM (1990) Calibration of methods for determining numbers of dorsal root ganglion cells. J Neurosci Methods 35:187-194.

Coleman JR (1990) Development of sensory systems in mammals. New York: Wiley.

Crissman RS, Warden RJ, Siciliano DA, Klein BG, Renehan WE, Jacquin MF, Rhoades RW (1991) Numbers of axons innervating mystacial vibrissa follicles in newborn and adult rats. Somatosens Motor Res 8: 103-109.

Davies A, Lumsden A (1984) Relation of target encounter and neuronal death to nerve growth factor responsiveness in the developing mouse trigeminal ganglion. J Comp Neurol 223:124-137.

Durham D, Woolsey TA (1984) Effects of neonatal whisker lesions on mouse central trigeminal pathways. J Comp Neurol 223:424-447.

Durham D, Woolsey TA (1985) Functional organization in cortical barrels of normal and vibrissae-damaged mice: a $\left({ }^{3} \mathrm{H}\right)$ 2-deoxyglucose study. J Comp Neurol 235:97-110.

Erzurumlu RS, Killackey HP (1983) Development of order in the rat trigeminal system. J Comp Neurol 213:365-380.

Frank E, Mendelson B (1990) Specification of synaptic connections between sensory and motor neurons in the developing spinal cord. $J$ Neurobiol 21:33-50.

Golden JP, Kana JZ, Davis J, Zahm DS, Jacquin MF (1993) Organization of the proximal segment of the infraorbital nerve at multiple intervals after axotomy at birth: a quantitative electron microscopic study in rat. J Comp Neurol, submitted.

Hand C, Craik RL, Gallo KG, Hand PG (1990) Additive functional subcortical changes con tribute to cortical alterations following sensory training. Soc Neurosci Abstr 16:828.

Henderson TA, Osborne PA, Srisumrid R, Woolsey TA, Johnson EM, Jacquin MF (1991) Fetal injections of nerve growth factor interrupts whisker-related pattern formation in brainstem. Soc Neurosci Abstr 17:10.

Henderson TA, Woolsey TA, Jacquin MF (1992) Infraorbital nerve blockade from birth does not disrupt central trigeminal pattern formation in the rat. Dev Brain Res 66:146-152.

Henderson TA, Rhoades RW, Bennett-Clarke CA, Osborne PA, Johnson EM, Jacquin MF (1993) NGF augmentation rescues first- and second-order neurons, but not brainstem or cortical whisker patterns, after infraorbital nerve injury at birth. J Comp Neurol, in press.

Hobart NH, Henderson TA, Renehan WE, Connors NA, Jacquin MF (1991) Mechanisms underlying rapid enlargement of spared-whisker projections after neonatal infraorbital nerve section. Soc Neurosci Abstr 17:1128.

Jacquin MF (1989) Structure-function relationships in rat brainstem subnucleus interpolaris. V. Functional consequences of neonatal infraorbital nerve section. J Comp Neurol 282:63-79.

Jacquin MF, Rhoades RW (1983) Central projections of the normal and "regenerate" infraorbital nerve in adult rats subjected to neonatal unilateral infraorbital lesions: a transganglionic horseradish peroxidase study. Brain Res 269:137-144.

Jacquin MF, Rhoades RW (1985) Effects of neonatal infraorbital lesions upon central trigeminal primary afferent projections in rat and hamster. J Comp Neurol 235:129-143.

Jacquin MF, Woerner D, Szczepanik AM, Riecker V, Mooney RD, Rhoades RW (1986) Structure-function relationships in rat brainstem subnucleus interpolaris. I. Vibrissa primary afferents. J Comp Neurol 243:266-279

Jacquin MF, Stennett RA, Renehan WE, Rhoades RW (1988) Structure-function relationships in rat brainstem subnucleus interpolaris. 
II. Low and high threshold trigeminal primary afferents. J Comp Neurol 267:107-130.

Jacquin MF, Chiaia NL, Klein BG, Rhoades RW (1989) Structurefunction relationships in rat brainstem subnucleus interpolaris. VI. Cervical convergence in cells deafferented at birth and a potential primary afferent substrate. J Comp Neurol 283:513-525.

Jensen KF, Killackey HP (1987) Terminal arbors of axons projecting to the somatosensory cortex of the adult rat. II. The altered morphology of thalamocortical afferents following neonatal infraorbital nerve cut. J Neurosci 7:3544-3553.

Killackey HP, Fleming K (1985) The role of the principal sensory nucleus in central trigeminal pattern formation. Dev Brain Res 22: 141-145.

Killackey HP, Jacquin MF, Rhoades RW (1990) Development of somatosensory system structures. In: Development of sensory systems in mammals (Coleman JR, ed), pp 403-429. New York: Wiley.

Klein BG, Rhoades RW (1985) Representation of whisker follicle intrinsic musculature in the facial motor nucleus of the rat. J Comp Neurol 232:55-69.

Klein BG, Renehan WE, Jacquin MF, Rhoades RW (1988) Anatomical consequences of neonatal infraorbital nerve transection upon the trigeminal ganglion and vibrissa follicle nerves in the adult rat. J Comp Neurol 268:469-488.

Kossut M, Hand P, Greenberg J, Hand CL (1988) Single vibrissal cortical column in SI cortex of rat and its alterations in neonatal and adult vibrissa-deafferented animals: a quantitative $2 D G$ study. J Neurophysiol 60:829-852.

McLean IW, Nakane PK (1974) Periodate-lysine paraformaldehyde fixative: a new fixative for immunoelectron microscopy. J Histochem Cytochem 22:1077-1083.

Melzer P, Yamakado M, Van der Loos H, Welker E, Dorfl J (1988) Plasticity in the barrel cortex of adult mouse: effects of peripheral deprivation on the functional map; a deoxyglucose study. Soc Neurosci Abstr 14:844.

O'Connor TP, van der Kooy D (1986) Cell death organizes the postnatal development of the trigeminal innervation of the cerebral vasculature. Dev Brain Res 27:223-233.

Renehan WE, Rhoades RW (1984) A quantitative electron microscopic analysis of the infraorbital nerve in the newborn rat. Brain Res 322:369-373.

Renehan WE, Rhoades RW, Jacquin MF (1989) Structure-function relationships in rat brainstem subnucleus interpolaris. VII. Primary afferent central terminal arbors in adults subjected to infraorbital nerve section at birth. J Comp Neurol 289:493-508.
Rhoades RW, Chiaia NL, Mooney RD, Klein BG, Renehan WE, Jacquin MF (1987) Reorganization of the peripheral projections of the trigeminal ganglion following neonatal transection of the infraorbital nerve. Somatosens Res 5:35-62.

Rhoades RW, Chiaia NL, Macdonald GJ, Jacquin MF (1989) The effect of fetal infraorbital nerve transection upon trigeminal primary afferent projections in the rat. J Comp Neurol 287:82-97.

Rhoades RW, Killackey HP, Chiaia NL, Jacquin MF (1990) Physiological development and plasticity of somatosensory neurons. In: Development of sensory systems in mammals (Coleman JR, ed), pp 431-459. New York: Wiley.

Rhoades RW, Renehan WE, Jacquin MF (1991) Mechanisms underlying deafferentation effects upon the developing trigeminal brainstem complex. In: Deafferentation syndrome: its pathophysiology and treatment (Nashold BS, Ovelmen-Levitt J, eds), pp 49-70. New York: Raven.

Senft SI, Woolsey TA (1991) Growth of thalamic afferents into mouse barrel cortex. Cereb Cortex 1:308-335.

Van der Loos H, Woolsey TA (1973) Somatosensory cortex: structural alterations following early injury to sense organs. Science 179:395398.

Waite PME (1984) Rearrangement of neuronal responses in the trigeminal system of the rat following peripheral nerve section. J Physiol (Lond) 352:425-445.

Waite PME, Jacquin MF (1992) Dual innervation of the rat vibrissae: responses of trigeminal ganglion cells projecting through deep or superficial nerves. J Comp Neurol 322:233-245.

Waite PME, de Permentier P (1991) The rat's postero-orbital sinus hair. I. Brainstem projections and the effect of infraorbital nerve section. J Comp Neurol 312:325-340.

Williams JR, de Permentier P, Waite PME (1992) The rat's posteroorbital sinus hair. II. Normal morphology and the increase in peripheral innervation with adjacent nerve section. J Comp Neurol 322: 213-223.

Wong-Riley MTT (1979) Changes in the visual system of monocularly sutured or enucleated cats demonstrable with cytochrome oxidase histochemistry. Brain Res 171:11-28.

Woolsey TA (1990) Peripheral alteration and somatosensory development. In: Development of sensory systems in mammals (Coleman JR, ed), pp 461-516. New York: Wiley.

Young PH, Zahm DS, Golden JP, Jacquin MF (1990) Axon numbers in spared supraorbital vibrissae follicle nerves following infraorbital nerve section at birth. Soc Neurosci Abstr 16:631. 